\title{
Strengths and strain energies of volcanic edifices: implications for eruptions, collapse calderas, and landslides
}

\author{
A. Gudmundsson \\ Department of Earth Sciences, Royal Holloway University of London, UK
}

Correspondence to: A. Gudmundsson (a.gudmundsson@es.rhul.ac.uk)

Received: 14 March 2012 - Revised: 1 June 2012 - Accepted: 10 June 2012 - Published: 19 July 2012

\begin{abstract}
Natural hazards associated with volcanic edifices depend partly on how fracture resistant the edifices are, i.e. on their strengths. Observations worldwide indicate that large fluid-driven extension fractures (dikes, inclined sheets), shear fractures (landslides), and mixed-mode fractures (ring dikes and ring faults) normally propagate more easily in a basaltic edifice (shield volcano) than in a stratovolcano. For example, dike-fed eruptions occur once every few years in many basaltic edifices but once every $10^{2-3} \mathrm{yr}$ in many stratovolcanoes. Large landslides and caldera collapses also appear to be more common in a typical basaltic edifice/shield volcano than in a typical stratovolcano. In contrast to a basaltic edifice, a stratovolcano is composed of mechanically dissimilar rock layers, i.e. layers with mismatching elastic properties (primarily Young's modulus). Elastic mismatch encourages fracture deflection and arrest at contacts and increases the amount of energy needed for a large-scale edifice failure. Fracture-related hazards depend on the potential energy available to propagate the fractures which, in turn, depends on the boundary conditions during fracture propagation. Here there are two possible scenarios: one in which the outer boundary of the volcanic edifice or rift zone does not move during the fracture propagation (constant displacement); the other in which the boundary moves (constant load). In the former, the total potential energy is the strain energy stored in the volcano before fracture formation; in the latter, the total potential energy is the strain energy plus the work done by the forces moving the boundary. Constantdisplacement boundary conditions favor small eruptions, landslides, and caldera collapses, whereas constant-load conditions favor comparatively large eruptions, landslides, and collapses. For a typical magma chamber (sill-like with a diameter of $8 \mathrm{~km}$ ), the strain energy change due to magmachamber inflation is estimated at the order of $10^{14} \mathrm{~J}(0.1 \mathrm{PJ})$.
\end{abstract}

For comparison, the surface energy needed to form a typical feeder dike is of the same order of magnitude, or $10^{14} \mathrm{~J}$. There are several processes besides magma-chamber inflation that may increase the strain energy in a volcano before eruption. Thus, during a typical unrest period with magmachamber inflation, the added strain energy in the volcano is large enough for a typical feeder dike to form. An injected dike, however, only reaches the surface and becomes a feeder if it is able to propagate through the numerous layers and contacts that tend to deflect or arrest dikes. The strong elastic mismatch between layers that constitute stratovolcanoes not only encourages fracture arrest, but also the storage of more strain energy (than in a typical basaltic edifice/shield volcano) before fracture formation and failure. It is thus through producing materials of widely different mechanical properties that stratovolcanoes become strong and resilient.

\section{Introduction}

Many stratovolcanoes are long-lived, tall and strong structures (Fig. 1). The tallest ones reach $6-6.9 \mathrm{~km}$ above sea level, 4-4.8 km above their surroundings, and their upper parts are as steep as $35-42^{\circ}$ (Simkin and Siebert, 1995, 2000; Frank, 2003; Rosi et al., 2003; Siebert et al., 2010). Given the steep slopes, small landslides are common (Reid, 2004; Boudon et al., 2007). For most stratovolcanoes, large landslides taking $20-30 \%$ of the cone material, however, are apparently not common and seem to require specific external loading, such as shallow magma intrusion or earthquakes (Tibaldi et al., 2006). 


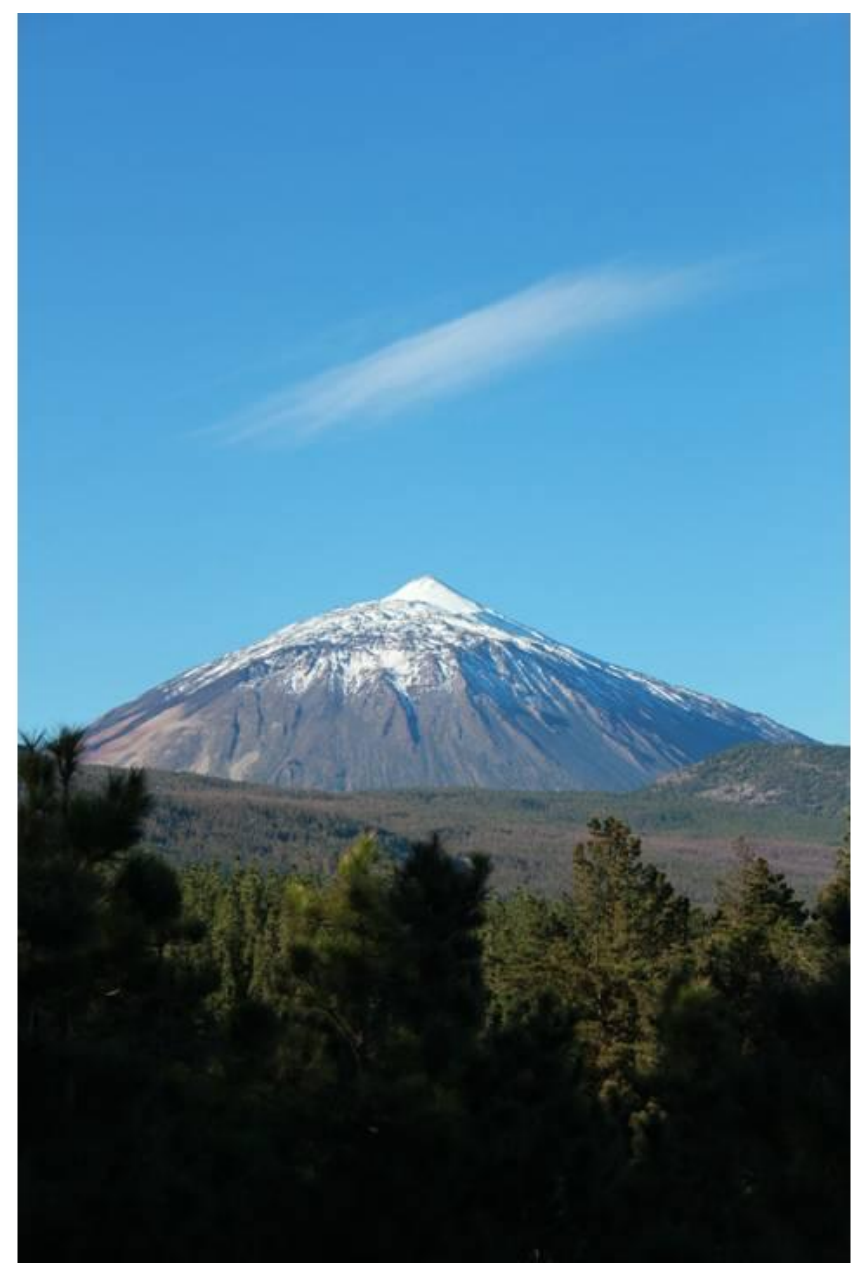

Fig. 1. The stratovolcano Teide in Tenerife, Canary Islands. View looking southwest, the summit of El Pico del Teide is at $3710 \mathrm{~m}$ a.s.l. The volcano as seen here stands about $1800 \mathrm{~m}$ above its surroundings, has steep slopes, and is composed of numerous lava flows, pyroclastic and sedimentary layers, and intrusions of various types and mechanical properties (cf. Figs. 3 and 10).

Some stratovolcanoes, over certain periods of time, may be subject to many landslides. Well-known examples include Stromboli in Italy, where four large landslides have occurred in the past 15 thousand years (Tibaldi, 2003), and Augustine in Alaska (composed of several overlapping lava domes), where some eleven lateral collapses have occurred in the past 2 thousand years (Beget and Kienle, 1992). Both these stratovolcanoes are highly active - Augustine being the most active volcano in the eastern part of the Aleutian Arc and Stromboli effectively the most active volcano in the world - and their high activity may be one reason for their relative instability and frequent landslides over these time periods. In comparison with basaltic edifices/shield volcanoes, however, large landslides appear less frequent in typical stratovolcanoes than in typical basaltic edifices.
Dike-fed eruptions are the most common type of largescale fracture failure of volcanic edifices. Some stratovolcanoes erupt once every 0.1-10 yr (Simkin and Siebert, 2000; Siebert et al., 2010), but these eruptions are mostly related to open central conduits, rare features, or lava lakes, rather than to feeder-dike formation and associated edifice failure. A common eruption frequency in a mature stratovolcano is once every several hundred to several thousand years (Simkin and Siebert, 1995, 2000; Frank, 2003; Rosi et al., 2003; Siebert et al., 2010).

Some clarification is needed as to what is meant by volcano failure. When we refer to magma-driven fracture failure of a volcano, what is meant in this paper is failure through dikes and inclined sheets. Many stratovolcanoes have central conduits. Only in very rare cases, however, and over short periods of time and at very shallow depths, are these conduits open cavities to the surface. Most commonly, the conduits are filled with rocks of various types. As is well known, many eroded conduits are exposed as plugs (necks) composed of breccias and (mainly dike and inclined sheet) intrusions. During eruptions from conduits, it is commonly a single dike that propagates through the conduit rocks and to the surface supplies magma to the eruption rather than the conduit as a whole.

This conclusion is strongly supported by the recent drilling into the conduit of the Mount Unzen volcano in Japan (Nakada et al., 2005). The results of the drilling show that the 500-m-thick conduit is, at $1.3 \mathrm{~km}$ depth below the summit of the volcano, composed primarily of volcanic breccias dissected by many dikes and igneous (pyroclastic) veins. The dikes range in thickness from 7 to $40 \mathrm{~m}$, are subvertical and subparallel, and strike perpendicular to the inferred trend of the minimum principal compressive stress, $\sigma_{3}$, in this part of the volcano. The dikes are sheet-like (not pipe-like), some multiple, and occur over the entire 500-m width of the conduit. Similar results have been obtained from detailed studies of Stromboli, Italy. Close to the central zone of the volcanic cone of Stromboli, well-exposed outcrops indicate that close to $100 \%$ of the uppermost part of the plumbing system is made of sheet-like dikes (Tibaldi et al., 2009). No circular or pipe-like conduits have been found. Furthermore, the active magma conduit itself is a dike (Casagli et al., 2009). Thus, even within a clear conduit zone, the supply of magma to the surface, and thus the condition for an eruption, in a stratovolcano may be, and presumably very often is, primarily through dikes.

The largest basaltic edifices (shield volcanoes) on Earth rise as much $9 \mathrm{~km}$ above the sea floor - some $15-17 \mathrm{~km}$ if the depression of the sea floor is taken into account (Rosi et al., 2003; Lockwood and Hazlett, 2010; Siebert et al., 2010; hvo.wr.usgs.gov/maunaloa) - but they often form clusters with unclear elevation reference levels (Simkin and Siebert, 1995, 2000; Frank, 2003; Rosi et al., 2003; Siebert et al., 2010). Most basaltic edifices are much smaller, and their slopes are generally gentle (Fig. 2). For example, the slope 


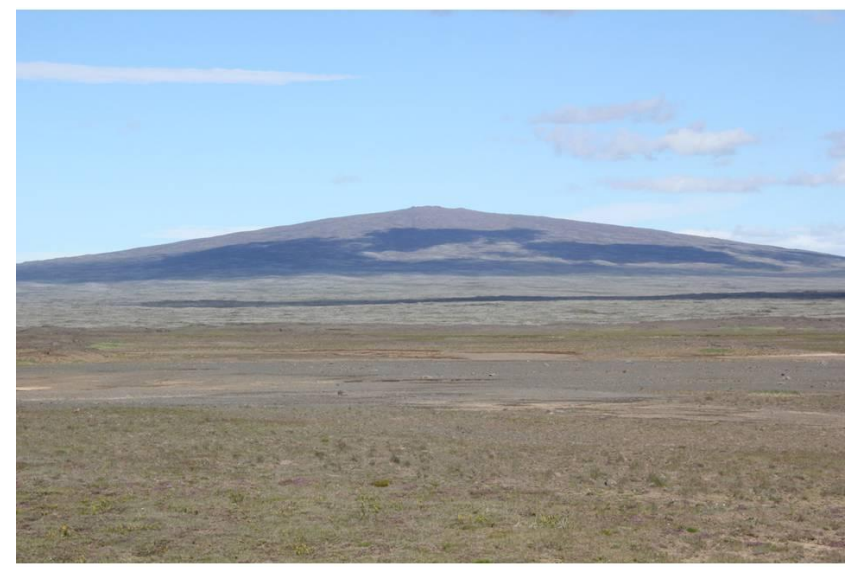

Fig. 2. Small shield volcano, the Holocene lava shield Skjaldbreidur in Southwest Iceland. View looking east, the top of the lava shield is at $1060 \mathrm{~m}$ a.s.l. and rises here some $700 \mathrm{~m}$ above its surroundings. The shield is composed almost exclusively of thin (0.5-2 m thick) pāhoehoe flow units with little or no scoria at the contacts between the layers.

of the subaerial parts of Kilauea and Mauna Loa is mostly 4$8^{\circ}$ (Walker, 2000). Large landslides are common in basaltic edifices (Oehler et al., 2005; Thompson et al., 2008), such as around the Big Island of Hawaii (Moore et al., 1994), the Canary Islands (Acosta et al., 2005), and Réunion (Oehler et al., 2005). Many large landslides are submarine; others are subaerial. There are more identified calderas hosted by stratovolcanoes than by basaltic edifices (Geyer and Marti, 2008), because there are many more known and classified stratovolcanoes than basaltic edifices (Simkin and Siebert, 1995, 2000; Frank, 2003; Rosi et al., 2003; Siebert et al., 2010; www.volcanodb.com). However, formation of and slip on existing ring faults of calderas appear to be more common in individual large basaltic edifices (Walker, 1988) than in individual stratovolcanoes (Newhall and Dzurisin, 1988). In many basaltic edifices, there is a dike-fed eruption once every 1-5 yr. For example, in Piton de la Fournaise (Réunion), Etna (Italy), and Mauna Loa (Hawaii) (Simkin and Siebert, 1995, 2000; Frank, 2003; Rosi et al., 2003; Siebert et al., 2010).

This paper has three main aims. The first is to explain why, in comparison with basaltic edifices (shield volcanoes), stratovolcanoes can maintain steeper slopes and appear to be less frequently subject to large-scale failure through dike-fed eruptions and large vertical (caldera) and lateral (landslide) collapses. Using field observations, and analytical and numerical models, I provide observational and theoretical evidence for stratovolcanoes being mechanically stronger structures than basaltic edifices. Other factors, of course, contribute to the steep slopes of stratovolcanoes, for example, the commonly high viscosities of their magmas and associated extrusives. Here, however, the focus is on the effects of mechanical strength. The second aim is to analyze the conditions for fracture propagation in volcanic edifices and how

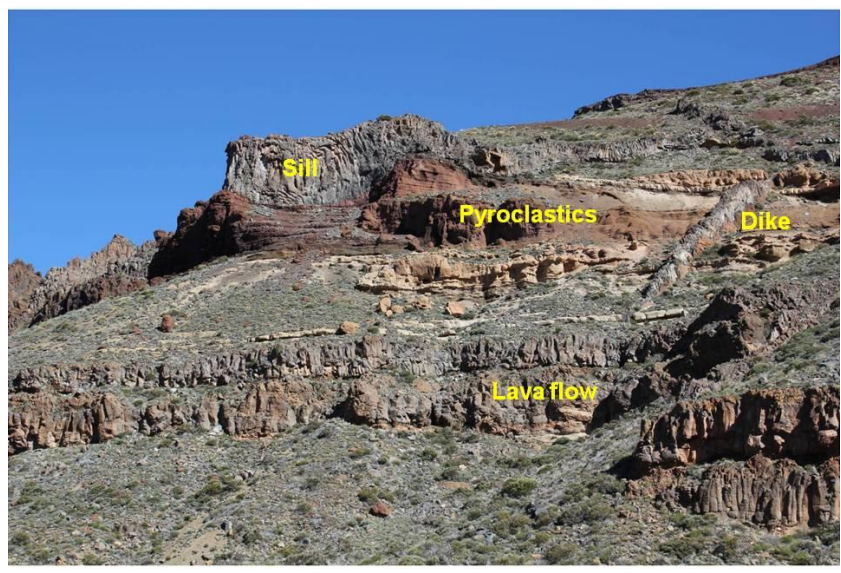

Fig. 3. Internal structure of a stratovolcano, here a part of the collapse caldera of Las Cañadas volcano in Tenerife, Canary Islands. View looking east, the caldera wall is about $300 \mathrm{~m}$ high. The rock units seen in the wall include felsic light-colored to brownish pyroclastic layers, several basaltic sills and lava flows, as well as a prominent basaltic dike. Many of these layers and rock units have widely different mechanical properties.

different boundary conditions have different implications for fracture growth. In particular, I discuss the difference between the conditions where the outer boundary of the volcanic edifice/rift zone does not move (constant displacement) and where it moves (constant load) during the fracture propagation. The third aim is to estimate the strain energy stored in a volcanic edifice during unrest and magma-chamber inflation and compare it with the surface energy needed for a fracture to propagate to the surface in a volcanic edifice. The fracture example used is a typical feeder dike, but the results are easily generalized to other fractures such as landslide faults (slip surfaces) and ring faults (caldera faults).

\section{Internal structure}

A stratovolcano consists of rocks of widely different origin and composition (Fig. 3). Pyroclastic material is as much as $50 \%$ of the volume of the volcano and ranges in composition from mafic to felsic. The lava flows and intrusions, primarily sills, inclined sheets, and dikes (Fig. 3), show a similar compositional range. The sedimentary rocks, mostly debris talus derived from erosion of the upper parts of the volcano, become buried by subsequent lava flows and pyroclastic flows and thereby a part of the volcano structure. Some welded pyroclastic layers may have a higher Young's modulus, i.e. be stiffer than, typical lava flows, whereas non-welded pyroclastic layers and many sedimentary layers are compliant (with a low Young's modulus) and thus softer than lava flows (Bell, 2000; Gudmundsson, 2011a).

A basaltic edifice consists mostly of basaltic lava flows (Fig. 4), sills, inclined sheets, and dikes. The lava flows and 


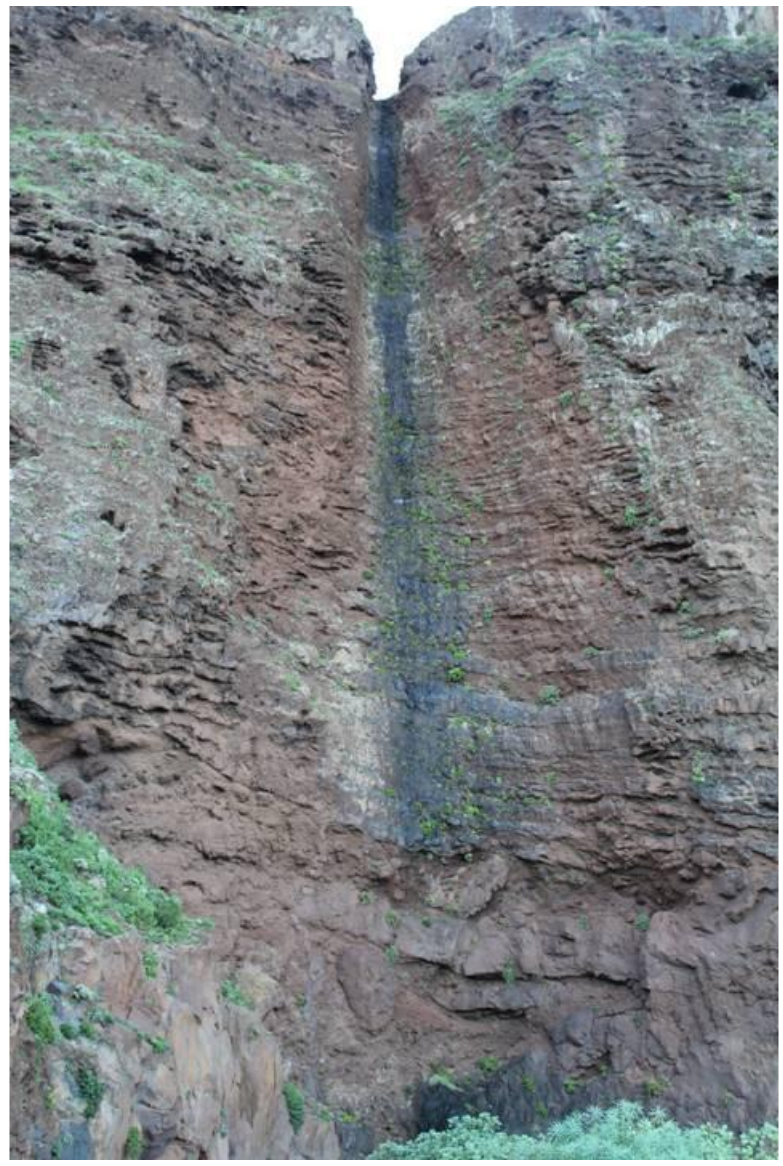

Fig. 4. Vertical cliff, about $120 \mathrm{~m}$ high, of thin basaltic lava flows at the peninsula of Teno in Tenerife, Canary Islands. View looking west, the cliff is composed of tens of lava flows, most of which are about one meter thick and with thin layers of scoria between the lava flows. Overall, the rocks that constitute the cliff, as well as many other sea cliffs in this old basaltic part of Tenerife, have very similar mechanical properties and the cliff functions effectively as a single mechanical layer.

intrusions contain numerous columnar joints which lower their effective stiffness. The joints also decrease the horizontal tensile strength to as low as $0.5 \mathrm{MPa}$ (Schultz, 1995), making it similar to the vertical tensile strength across contacts between 'a'à lava flows and between flow units in pāhoehoe flows. (A stratovolcano also contains lava flows and intrusions with numerous joints, but in addition it contains many pyroclastic and sedimentary layers with very different joint patterns and mechanical properties from those of the lava flows and intrusions). A basaltic edifice is thus made of rock units, layers, and contacts with mechanical properties that vary much less than those in a stratovolcano (Fig. 4).

One principal measure of the toughness of layered and laminated materials is the frequency with which fractures become deflected and arrested at interfaces or contacts between the layers (He and Hutchinson, 1989; Hutchinson, 1996). In a
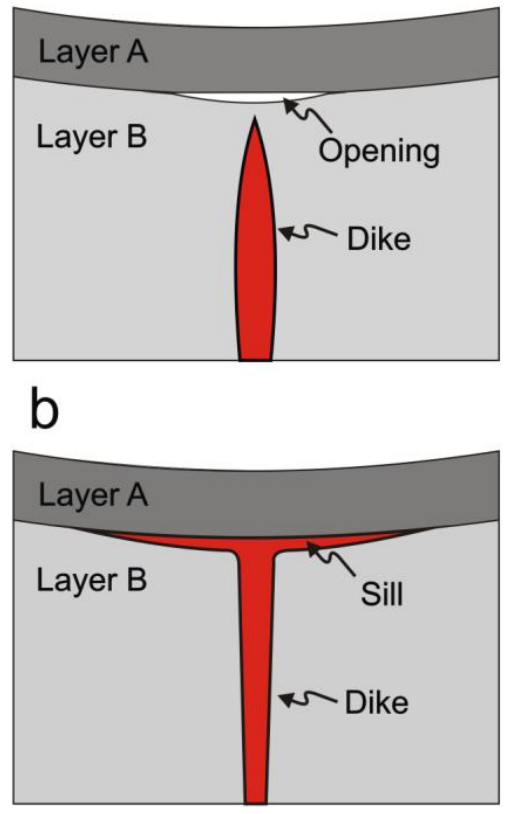

Fig. 5. (a) Schematic presentation of boundary element-model results showing opening, debonding or delamination, of a weaker contact between stiffer layers ahead of an overpressured (10 MPa) propagating dike. (b) If the dike reaches the contact, it may either become deflected into a sill (Figs. 7 and 10), as indicated here, or become arrested (Figs. 8 and 10).

fact, composite materials are made tough by arranging their parts so as to encourage deflection and arrest of fractures. Fracture deflection and arrest, such as of dikes, is common in rocks, particularly at contacts between layers of contrasting mechanical properties, i.e. layers with an elastic mismatch.

\section{Fracture deflection and arrest}

Deflection and arrest of rock fractures at contacts, and thus much of the toughness of a volcanic edifice, is primarily controlled by three related factors: (1) the tensile stresses ahead of the fracture and thus the tensile strength of the contact versus that of the adjacent rock layers; (2) rotation of the local principal stresses at the contact; (3) the material toughness of the contact in comparison with the material toughness of the adjacent rock layers.

The first factor can be illustrated by a contact opening up because of induced tensile stresses ahead of a dike tip (Fig. 5), referred to as the Cook-Gordon debonding or delamination (Gudmundsson, 2009, 2011b). In a homogeneous, isotropic material the tensile stress ahead of, and parallel to, an extension fracture such as a dike is about $20 \%$ of the stress perpendicular to the fracture. Opening of contacts between 


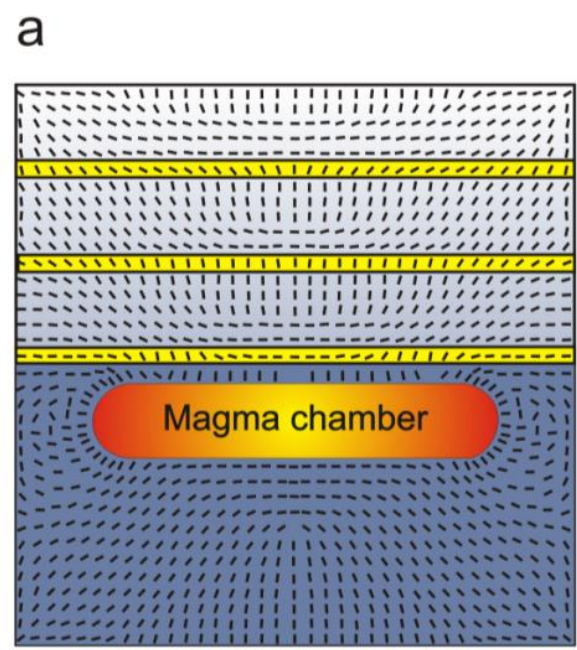

b

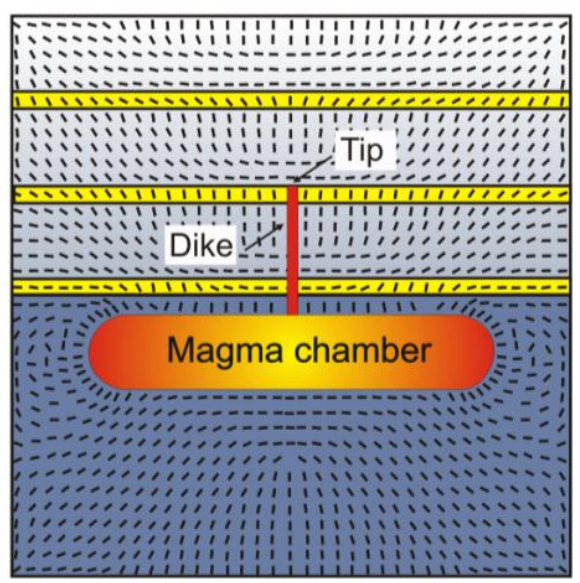

Fig. 6. Dike arrest due to principal stress rotation at contacts between dissimilar rocks. In this finite-element model, the only loading is magmatic excess pressure (5 MPa) in the magma chamber, located in a layer with a stiffness of $40 \mathrm{GPa}$. The thick (light blue) and thin (yellow) layers have stiffnesses of $100 \mathrm{GPa}$ and $1 \mathrm{GPa}$, respectively. The direction of the principal compressive stress, $\sigma_{1}$, is indicated by ticks (short lines). (a) State of stress before dike injection. (b) The dike follows the $\sigma_{1}$-ticks and, depending on its overpressure and the elastic mismatch (Fig. 9) across the contact, becomes arrested (as seen here) or changes into a sill (Figs. 7 and 10).

mismatching rock layers is common close to the surface, often resulting in fracture deflection or arrest.

The second factor, rotation of the principal stresses, occurs frequently at contacts between dissimilar rocks at various crustal depths (Fig. 6). Since dikes and other extension fractures do not normally propagate perpendicular to $\sigma_{1}$, (but rather perpendicular to $\sigma_{3}$ ), a vertically propagating dike that meets a layer where the local $\sigma_{1}$ has changed from being vertical to horizontal either becomes deflected along the contact (Fig. 7) or arrested (Fig. 8).

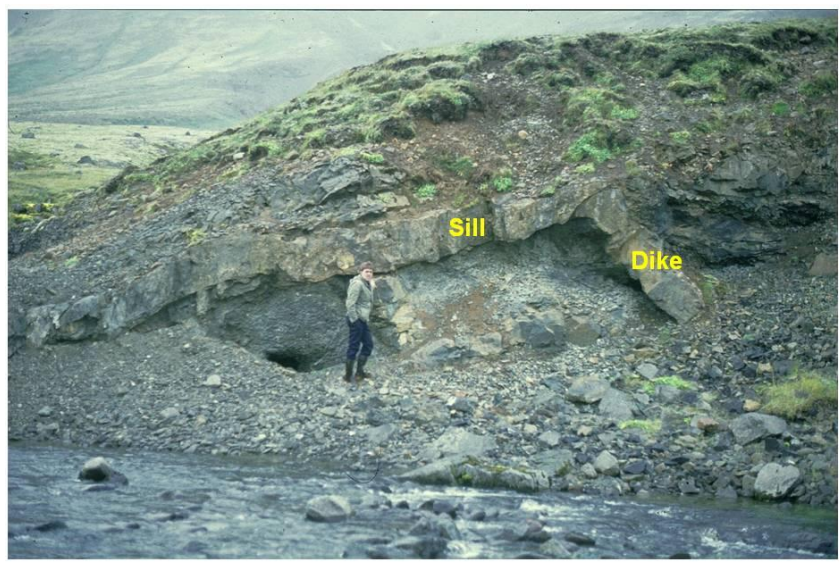

Fig. 7. Dike (inclined sheet) deflected into a sill at a contact between dissimilar layers in the Tertiary areas of West Iceland. The layer below the sill (in front of which the person is standing for scale) is softer (more compliant) than the basaltic lava flow on the top of the sill.

The third factor is best analyzed as follows. The total energy release rate $G_{\text {total }}$ for a mixed-mode (extension and shear) loading is (Broberg, 1999; Gudmundsson, 2011a, b)

$$
\begin{aligned}
G_{\text {total }} & =G_{\mathrm{I}}+G_{\mathrm{II}}+G_{\mathrm{III}} \\
& =\frac{\left(1-v^{2}\right) K_{\mathrm{I}}^{2}}{E}+\frac{\left(1-v^{2}\right) K_{\mathrm{II}}^{2}}{E}+\frac{(1+v) K_{\mathrm{III}}^{2}}{E}
\end{aligned}
$$

where $G$ is energy release rate (see Sect. 5), $v$ is Poisson's ratio, $E$ is Young's modulus, and $K$ is the stress-intensity factor. The critical value of $G$ is referred to as the material toughness, given as $\mathrm{J} \mathrm{m}^{-2}$. The critical value of $K$ is referred to as fracture toughness, given as $\mathrm{Pa}^{1 / 2}$. This form of the equation assumes plane-strain conditions; the subscripts I-III for $G$ and $K$ denote the loading modes. In geology, a mode I crack model is suitable for extension fractures such as dikes, a mode II crack model for many dip-slip (normal and reverse) faults, and a mode III crack model for many strike-slip faults.

For an extension fracture such a dike (Figs. 3 and 5-8), the total energy release rate, $G_{\mathrm{I}}$, is given by the first term on the right-hand side of the equality sign in Eq. (1). Deflection of the fracture along a contact normally involves more than one loading mode (He and Hutchinson, 1989; Hutchinson, 1996), a mixed mode, in which case the total energy release rate is a combination of, for example, $G_{\mathrm{I}}$ and either $G_{\mathrm{II}}$ or $G_{\text {IIII }}$. Thus, to deflect an extension fracture from its normal path and propagate it along a contact between layers (as, say, mode II) for a while requires more energy per unit extension of fracture than a pure mode I propagation.

In addition, the path of a deflected fracture normally becomes longer than the path of a vertical extension fracture, which adds to the energy needed for the propagation of the mixed-mode fracture. This follows because the stressintensity factor $K$ depends on the length of the fracture. For 


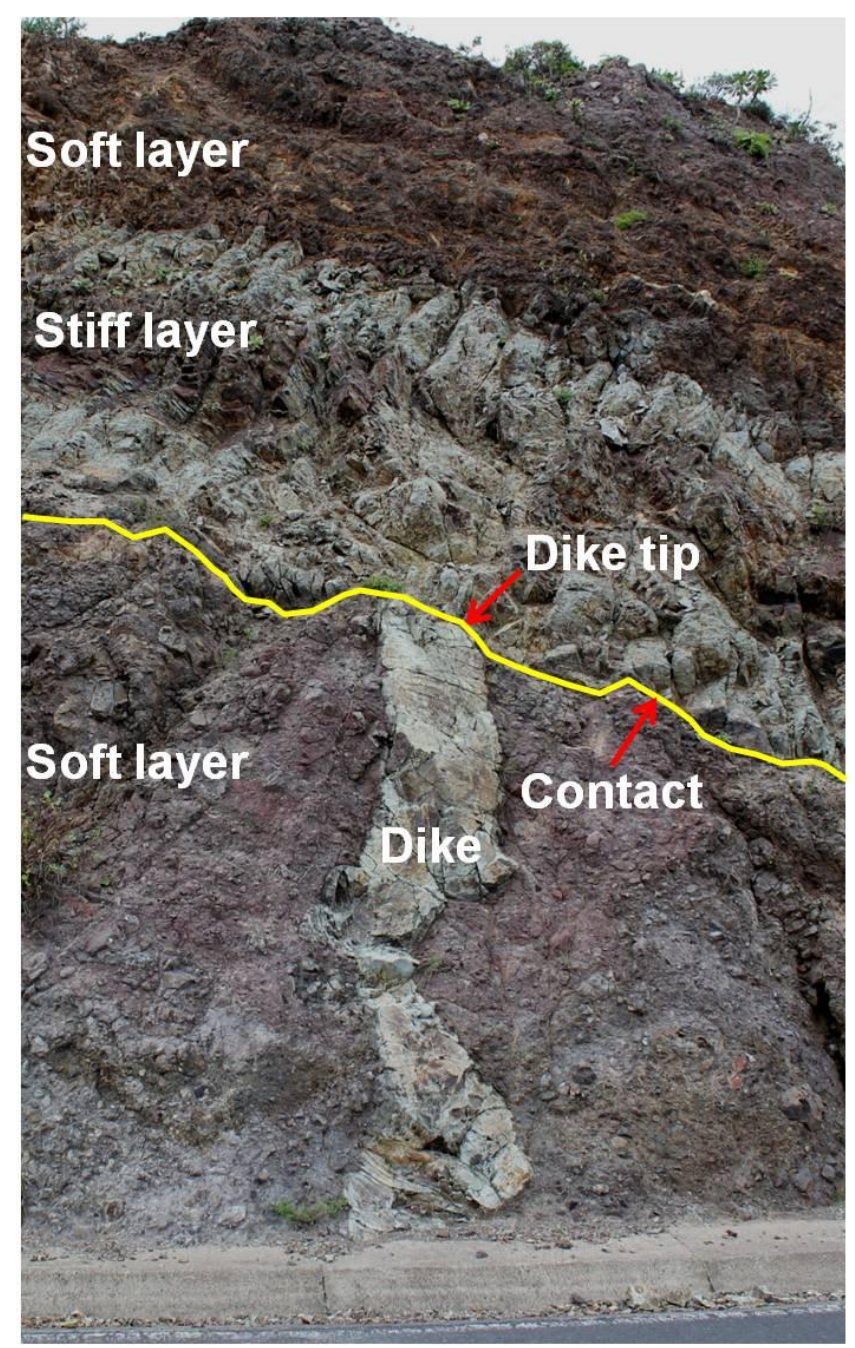

Fig. 8. Arrested basaltic dike at a contact between dissimilar rocks in Tenerife, Canary Islands. The stiff host rock is an inclined, basaltic sheet, whereas the soft rocks are altered breccias. The maximum dike thickness is $0.8 \mathrm{~m}$.

example, for a model I crack model of a dike (Figs. 3, 5 and $8), K_{\mathrm{I}}=P_{\mathrm{o}}[\pi a]^{1 / 2}$, where $P_{\mathrm{o}}$ is the magmatic overpressure driving the dike and $a$ is the dip dimension (the vertical path length) for a dike injected from a magma chamber. Deflected (Fig. 7) and arrested (Fig. 8) dikes and other fractures in a volcano indicate that the volcano has a comparatively high material toughness, i.e. is fracture resistant and strong.

The tendency to fracture deflection at contacts is indicated by the Dundurs' elastic extensional mismatch parameter $\alpha_{D}$ (He and Hutchinson, 1989; Hutchinson, 1996):

$\alpha_{\mathrm{D}}=\frac{E_{1}-E_{2}}{E_{1}+E_{2}}$

where $E$ is the plane-strain extensional Young's modulus (stiffness). Deflection of a vertical fracture along a horizontal contact is favored when the stiffness of the layer hosting the

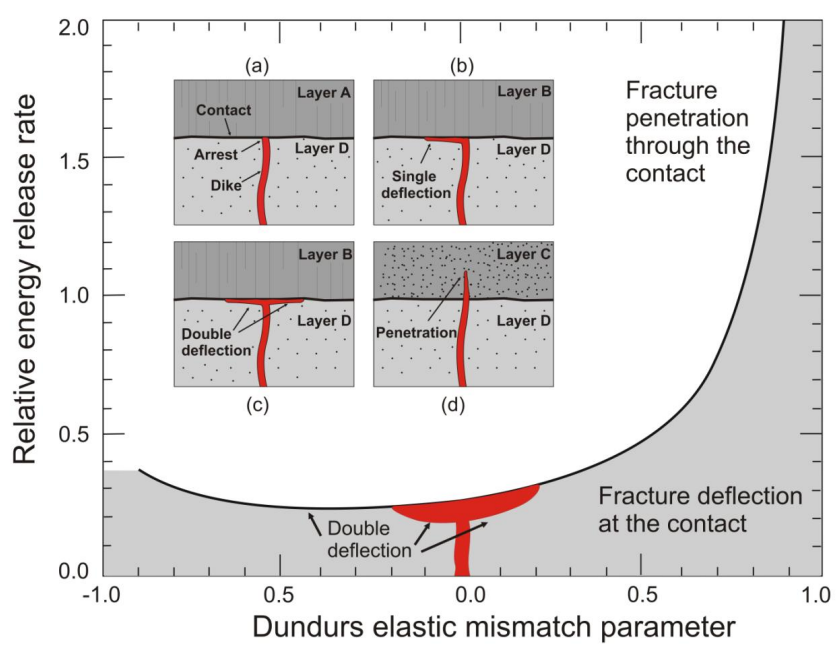

Fig. 9. Ratio of strain energy release rate, a measure of material toughness, to that of Dundurs' elastic mismatch parameter $\alpha_{\mathrm{D}}$ (data from He and Hutchinson, 1998 and Hutchinson, 1996). Inset: on meeting a contact, a fracture (here a dike) may become (a) arrested, (b) singly deflected, (c) doubly deflected, or (d) penetrate the contact. Layers A and B are stiffer than, whereas layer C has the same stiffness as, layer D. With no elastic mismatch across the contact, $\alpha_{\mathrm{D}}=0.0$, and fracture deflection occurs only if contact toughness is about $25 \%$ of the toughness of the layers A, B and C. When the mismatch increases $\left(\alpha_{\mathrm{D}}\right.$ increases from 0.0 toward 1.0), deflection occurs even if the contact toughness becomes higher than the toughness of the adjacent layers.

fracture $\left(E_{2}\right)$ and below the contact is less than that of the layer above the contact $\left(E_{1}\right)$. Theoretically, the tendency to fracture arrest or deflection varies positively with $\alpha_{\mathrm{D}}$ (Eq. 2; Fig. 9), i.e. with increasing difference between $E_{1}$ and $E_{2}$, as is confirmed in experiments (Kim et al., 2006; Lee et al., 2007).

From Eq. (2) and Figs. 3 and 5-9, what follows is that fracture deflection and/or arrest at a contact is encouraged when the mechanical properties, in particular Young's modulus, on either side of the contact are very different, giving rise to an elastic mismatch. By contrast, deflection along contacts is discouraged when the properties are similar or the same on either side of the contact (Figs. 4 and 9).

There is thus generally a much stronger tendency to deflection and/or arrest of fractures on meeting contacts between layers in a typical stratovolcano (Figs. 1, 3 and 10b) than in a typical basaltic edifice (Figs. 2, 4 and 10a). This is because elastic mismatch between layers is much more common, and generally much greater, in a stratovolcano than in a basaltic edifice. These theoretical conclusions are in good agreement with the results of a study of 165 dikes exposed in the uppermost $200 \mathrm{~m}$ of the caldera walls of the stratovolcano Miyakejima (Japan), the wall being the result of a caldera collapse in the year 2000 (Geshi et al., 2010, 2012). Even at such a shallow depth (less than $200 \mathrm{~m}$ below the surface), $93 \%$ of the 

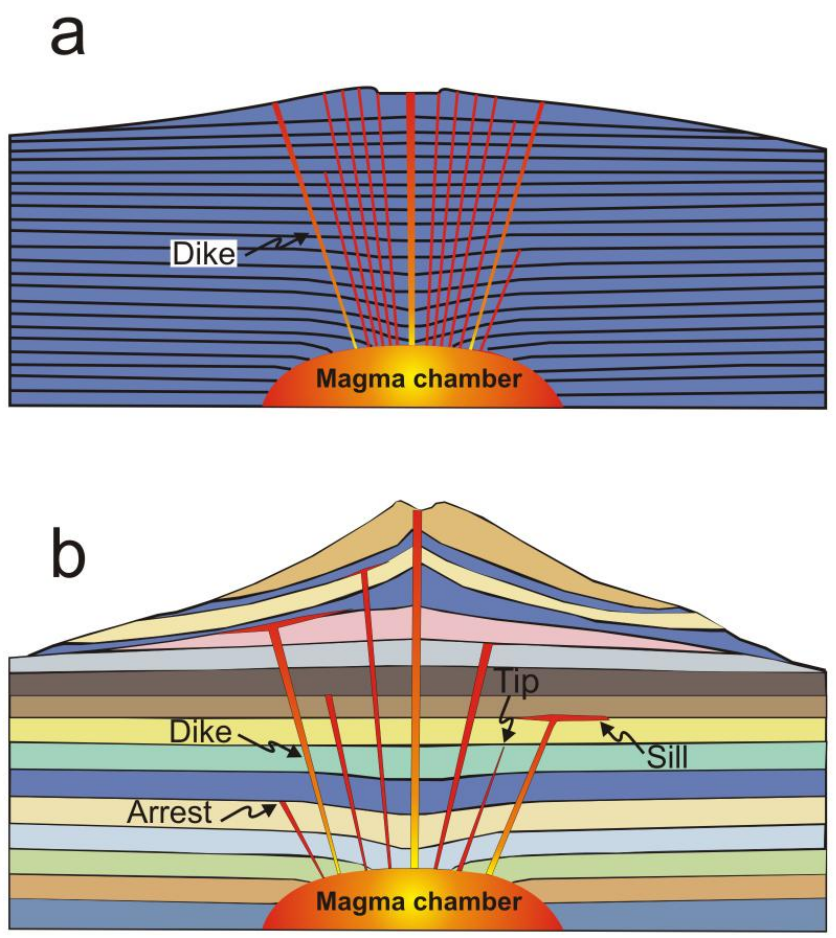

Fig. 10. (a) A basaltic edifice is composed primarily of mechanically similar layers so that, once initiated, landslide faults (or slip surfaces or failure planes), ring faults, and dikes have a comparatively high probability of reaching the surface, as indicated here by the many feeder dikes. (b) A stratovolcano is composed of mechanically dissimilar layers so that faults and dikes have comparatively low probability of reaching the surface, as indicated here by the many arrested and deflected (into sills) dikes.

exposed dikes are arrested, mostly at contacts between stiff lava flows and softer tuff layers - as predicted by the three fracture-arrest mechanisms discussed previously (cf. Figs. 5$10)$.

\section{Energies of a volcanic edifice}

While the arrest of a fracture depends on the mechanisms discussed above, its initiation and propagation depend largely on the energy stored in the volcanic edifice prior to fracture initiation. During an unrest period in a volcanic edifice, the associated hazards depend on how much energy is available to drive the fracture propagation that eventually gives rise to a volcanic eruption, a caldera collapse, or a large landslide. There are various forms of energy associated with volcanic edifices. These include thermal, kinetic, seismic, hydraulic potential, (elastic) potential, and strain energies. Thermal energy is related to the heat released from gas, pyroclastic materials, and lava flows, but is also transferred from the magma chamber to the host rock and to the surface. Kinetic energy is related to the explosive activity whereby pyroclastic materials (fragments) of various size, shapes, velocities, and temperatures are ejected from the eruptive vents. Seismic energy involves volcanic earthquakes, such as are generated during the upward propagation of a feeder dike, as well as during the volcanic tremor. Hydraulic potential energy results from the fact that fluids (magma and gas) are driven from a higher to a lower potential energy. This energy is thus reflected in the pressure/hydraulic gradient that drives the magma and gas to the surface during an eruption.

While thermal energy may contribute to the energy needed for a feeder-dike (or caldera ring-dike) propagation (such as through thermal stresses), it is primarily the (elastic) potential energy stored in the volcano that allows feeder-dikes, caldera faults, and landslide faults to form. Here the focus is thus on the (elastic) potential energy and its contribution to fracture formation in volcanic edifices.

When a volcanic edifice is loaded, potential energy is stored in its rock layers and units. In general, the loads may be forces, moments, stresses, strains, or displacements, or combinations of these. In the present analysis, the loading is supposed to be primarily related to inflation of the associated magma chamber. In this section, the focus is on simple magma-chamber inflation (and deflation) models, in particular the "Mogi model" (Mogi, 1958; Kusumoto and Gudmundsson, 2009), and how they relate to thermodynamic principles and the storage of potential energy during unrest periods. In Sect. 5, I show how the stored potential energy relates to fracture formation in the volcanic edifice.

Consider first a spherical model of a magma chamber. Let the depth to its center $d$ be much larger than its radius $R_{1}$ (Fig. 11). The standard solution is given for a sphere subject to a total pressure (rather than the excess pressure discussed below) as the only loading. For a magma chamber, the total pressure $p_{\mathrm{t}}$ may be given as $p_{\mathrm{t}}=p_{\mathrm{e}}+p_{l}$, where $p_{\mathrm{e}}$ is the excess pressure and $p_{l}$ the lithostatic pressure in the magma chamber. For convenience, the margin of the volcanic edifice or crustal segment hosting the chamber is also assumed to be a sphere with a radius $R_{2}$ where $R_{2} \gg R_{1}$ and there is lithostatic stress or pressure $p_{1}$ at $R_{2}$.

Using spherical polar coordinates $(r, \theta, \varphi), r$ is the radius vector (distance), $\theta$ is the angle between the radius vector $r$ and a fixed axis $z$, and $\varphi$ is the angle measured around this axis (Gudmundsson, 2011a). The total magmatic pressure in the chamber $p_{\mathrm{t}}$ generates a compressive radial stress $\sigma_{\mathrm{r}}$ :

$\sigma_{\mathrm{r}}=p_{\mathrm{t}}\left(\frac{R_{1}}{r}\right)^{3}+p_{l}\left[1-\left(\frac{R_{1}}{r}\right)^{3}\right]$

Because of spherical symmetry, the two other principal stresses $\sigma_{\theta}$ and $\sigma_{\varphi}$ are equal and given as

$\sigma_{\theta}=\sigma_{\varphi}=-\frac{p_{\mathrm{t}}}{2}\left(\frac{R_{1}}{r}\right)^{3}+\frac{p_{l}}{2}\left[\left(\frac{R_{1}}{r}\right)^{3}+2\right]$

Magma-chamber inflation or deflation occurs if the magmatic pressure in the chamber is above or below the 


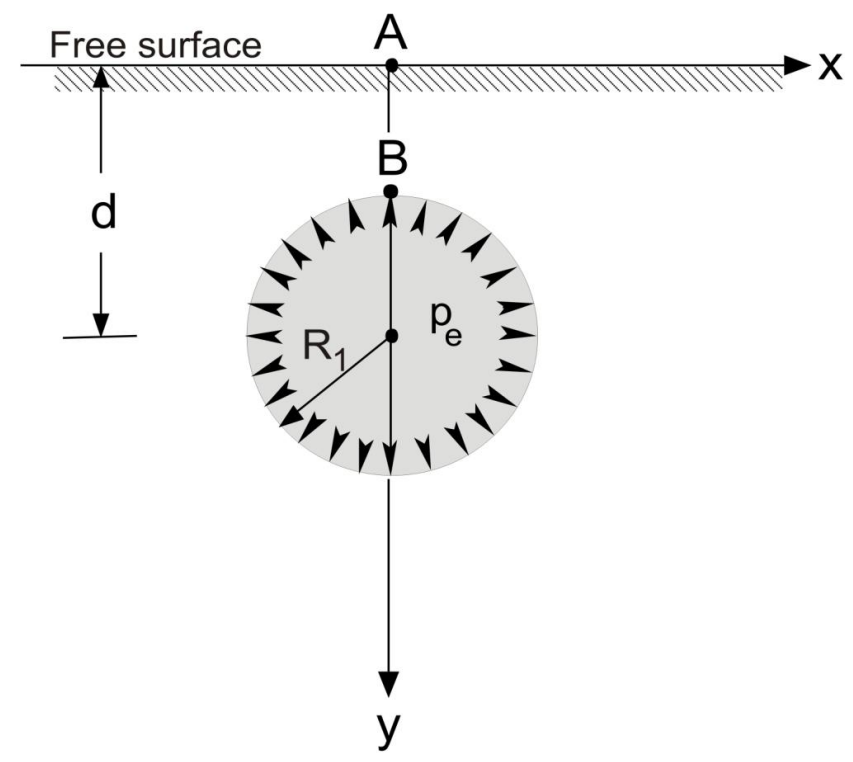

Fig. 11. Totally fluid, spherical magma chamber, the depth to its center being denoted by $d$. The chamber radius is $R_{1}$, and it is subject to magmatic excess pressure $p_{\mathrm{e}}$ as the only loading. The point directly above the center of the magma chamber $A$ would be the location of fissure eruptions in case the chamber rupture was at point $B$. Many spherical chambers, and chambers of other geometries, rupture and inject dikes and inclined sheets along their entire upper boundaries (cf. Gudmundsson, 2006).

lithostatic pressure in the host rock. Thus, it is more convenient to use the magmatic excess magma pressure $p_{\mathrm{e}}$, defined as the total pressure minus the normal stress (here, the lithostatic pressure), instead of the total pressure $\mathrm{p}_{\mathrm{t}}$. During magma-chamber inflation, the excess pressure must increase with time, whereas during deflation it must decrease with time. Using excess pressure, Eqs. (3) and (4) may be rewritten in the form:

$$
\begin{aligned}
& \sigma_{\mathrm{r}}=p_{\mathrm{e}}\left(\frac{R_{1}}{r}\right)^{3} \\
& \sigma_{\theta}=\sigma_{\varphi}=-\frac{p_{\mathrm{e}}}{2}\left(\frac{R_{1}}{r}\right)^{3}
\end{aligned}
$$

Consider next the special case of a very small spherical chamber, so that $R_{1} \ll d$ and $R_{1} \rightarrow 0$ but that the product of excess pressure and chamber radius, $p_{\mathrm{e}} R_{1}^{3}$, is still finite. This is the model of a "point pressure" or a nucleus of strain, initially used by Anderson (1936) to explain cone sheets and ring dikes, and subsequently referred to as the "Mogi model" in surface-deformation studies of volcanoes during unrest periods (Mogi, 1958; Kusumoto and Gudmundsson, 2009). Since pressure has the units of $\mathrm{N} \mathrm{m}^{-2}$ and volume has the units of $\mathrm{m}^{3}$, it follows that a "point pressure" has the units of $\mathrm{N}$ m, i.e. joules. This means that the "point-pressure" model is a measure of the energy stored in the volcano during inflation. The "point-pressure" or strain-nucleus energy $U_{\mathrm{n}}$ may be expressed as:

$U_{\mathrm{n}}=p_{\mathrm{e}} R_{1}^{3}$

It should be noted that, here, $R_{1}$ is the radius of the point source or chamber and $p_{\mathrm{e}}$, the excess pressure, is the pressure above lithostatic and thus the added pressure (change in pressure) that is responsible for the inflation - eventually, perhaps, resulting in magma-chamber rupture and dike injection. The model is commonly formulated in terms of magmachamber volume change $\Delta V_{\mathrm{c}}$ during the inflation, as is discussed below.

This model is a special case where the chamber is assumed small and totally molten. A more general case of a partially molten magma chamber can be derived as follows. If the volume of magma received (from a deeper source) by a porous magma chamber of total volume $V_{\mathrm{c}}$ is denoted by $V_{\text {re }}$, then the excess pressure in the chamber $p_{\mathrm{e}}$ is given by (cf. Gudmundsson, 2006):

$p_{\mathrm{e}}=\frac{V_{\mathrm{re}}}{\gamma\left(\beta_{\mathrm{m}}+\beta_{\mathrm{c}}\right) V_{\mathrm{c}}}$

where $\gamma$ is the melt fraction (porosity) of the magma chamber, $\beta_{\mathrm{m}}$ is the magma compressibility, and $\beta_{\mathrm{c}}$ is the compressibility of the host rock of the magma chamber. Substituting Eq. (8) for $p_{\mathrm{e}}$ in Eq. (7), and using a $=R_{1}$, we get the strain-nucleus energy as:

$U_{\mathrm{n}}=\frac{V_{\mathrm{re}} a^{3}}{\gamma\left(\beta_{\mathrm{m}}+\beta_{\mathrm{c}}\right) V_{\mathrm{c}}}$

To see how the equations above relate to more general principles, consider the first law of thermodynamics, which may be written in the form:

$\Delta U=\Delta Q+\Delta W$

where $\Delta U$ is the change in internal energy of the system (here the volcano), $\Delta Q$ is the heat received by the system, and $\Delta W$ is the work done on the system. These are the standard definitions in physics and chemistry (e.g. Atkins and de Paula, 2010; Blundell and Blundell, 2010). (In engineering it is common to consider the work done by the system on its surroundings and provide a negative sign for $\Delta W$ ).

When a magma chamber shrinks as magma flows out of it during an eruption, there is inward displacement of the chamber boundary/walls, so that there is work done. The work done is negative, since the volume is decreasing and the associated energy is decreasing. This follows because the maximum energy stored in the host rock existed at the time when there was maximum inflation of the chamber just before it ruptured and magma started to flow out of it towards the surface. Since magma is flowing out of the chamber during the eruption and to the surface where it cools down, the 
heat received by the chamber (the system) $\Delta Q$ is also negative, meaning that heat is transported (by the erupted magma) out of the system, i.e. the chamber.

It follows from these considerations that the energy change in the volcanic edifice or system during an eruption is negative, i.e. the internal energy decreases. It is this energy decrease that drives the eruption. The heat lost can be calculated from the solidification of magma from, say, $1100^{\circ} \mathrm{C}$ to $25^{\circ} \mathrm{C}$, but is not considered in the calculations below which focus on the work and its relation to the potential energy available to drive eruptions, landslides, and caldera collapses.

Work is defined as force time displacement or distance in the direction of the force. The excess pressure is force per unit area of the magma-chamber boundary. It follows that the work done, $\Delta W$, is given by (positive if expansion, negative if shrinkage):

$\Delta W=p_{\mathrm{e}} \Delta V_{\mathrm{c}}$

where $\Delta V_{\mathrm{c}}$ is the change in volume of the magma chamber during the eruption. The magmatic excess pressure has the units of pascal, newtons per square meter, whereas the volume change has the units of cubic meters. We thus have $\mathrm{N} \mathrm{m}^{-2} \times \mathrm{m}^{3}=\mathrm{Nm}$, namely joule, which is the unit of work and energy.

In Eq. (10), it is assumed that the excess pressure is constant during the magma-chamber volume change. This is normally not the case. For variable excess pressure, the work during the magma-chamber volume change is given by (positive if expansion, negative if shrinkage):

$d W=p_{\mathrm{e}} d V_{\mathrm{c}}$

so that the total work $(W)$ during the magma-chamber shrinkage or compression becomes:

$W=\int_{V_{\mathrm{i}}}^{V_{\mathrm{f}}} p_{\mathrm{e}} d V$

where $V_{\mathrm{i}}$ and $V_{\mathrm{f}}$ are the initial and final volumes, respectively. In the point-pressure model, the magmatic excess pressure is assumed constant. Comparison of Eq. (7) and Eqs. (11) and (12) further shows that the point-pressure model is simply a measure of the energy or work done by the expanding (inflating) or contracting (deflating) magma chamber in a volcano.

The work done during the shrinkage of the magma chamber, however, is primarily used to keep the magmatic excess pressure positive (or else no magma could be driven out of the chamber). Thus, this work is not readily available to generate fractures, such as are needed for the formation of dykes, caldera collapses, and landslides, to which we turn now.

\section{Energy available for fracture formation}

Energy is needed as input into the volcanic edifice to create the new fracture surfaces associated with the formation of a dike, a ring-fault, or a landslide fault. This energy is referred to as surface energy. It can be explained at an atomic level as follows. To form a fracture, two atomic planes must be moved away from each other to a distance where there are no interacting forces between the planes. The separation requires work, i.e. energy, namely surface energy $W_{\mathrm{s}}$. Because $W_{\mathrm{s}}$ represents energy that must be put into the system, in this case the volcanic edifice, it is regarded as positive.

For a fracture to form, the total energy of the volcanic edifice $U_{\mathrm{t}}$ must be large enough to overcome the surface energy $W_{\mathrm{s}}$. The total energy may be regarded as composed of two parts (cf. Sanford, 2003; Anderson, 2005):

$U_{\mathrm{t}}=\Pi+W_{\mathrm{s}}$

where $\Pi$ is the (elastic) potential energy of the volcanic edifice and is supplied from two sources, i.e. the strain energy $U_{0}$ and external applied load or generalized force $F$. The strain energy $U_{0}$, or rather the strain-energy change, is stored in the edifice when it is loaded. Here the focus is on the strain energy stored during magma-chamber inflation, i.e. the energy change prior to failure and fracture formation.

If a dike, a ring-fault, or a landslide fault is to form or reactivate, the total energy $U_{\mathrm{t}}$ in Eq. (14) must either remain constant or decrease. Fracture growth under equilibrium conditions is thus the condition where $U_{\mathrm{t}}=$ constant. For the fracture to propagate, new surface area $d A$ must be generated. It follows from Eq. (14) and the condition $U_{\mathrm{t}}=$ constant that, for equilibrium condition:

$\frac{d U_{\mathrm{t}}}{d A}=\frac{d \Pi}{d A}+\frac{d W_{s}}{d A}=0$

so that

$-\frac{d \Pi}{d A}=\frac{d W_{s}}{d A}$

Using Eq. (16) we may define the energy release rate $G$ :

$G=-\frac{d \Pi}{d A}$

which is then the energy available to drive the fracture propagation. More specifically, fracture extension occurs if the energy release rate reaches the critical value on the right-hand side of Eq. (16):

$G_{\mathrm{c}}=\frac{d W_{s}}{d A}$

where $G_{\mathrm{c}}$ is referred to as the material toughness of the rock.

Fracture formation and propagation can be formulated in terms of two principal boundary conditions that provide different energy sources for the fracture propagation. One is the displacement control, i.e. a fixed-grip or constant displacement boundary condition. This means that during the fracture propagation within, say, a rift zone in the volcanic edifice, 


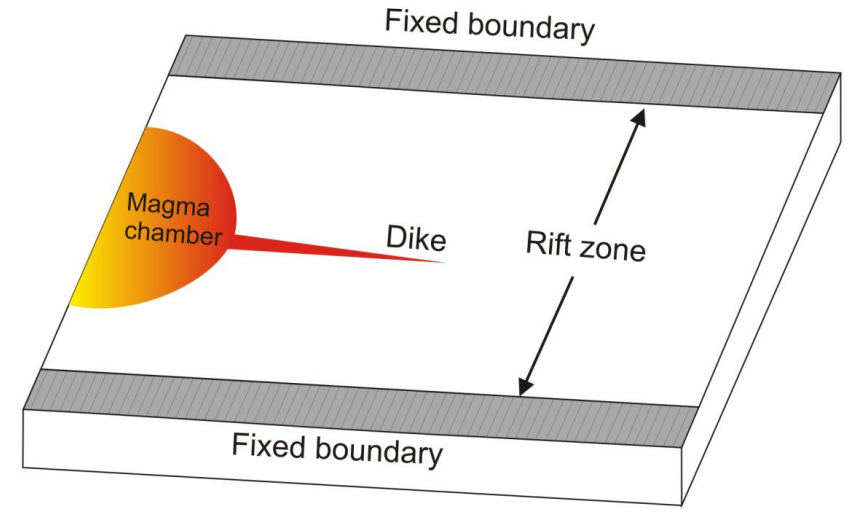

Fig. 12. Dike injected laterally from a magma chamber located in a volcanic edifice associated with a rift-zone segment. A fixed boundary means that the boundary displacement is constant during the dike emplacement - i.e. the boundary does not move.

there is a prescribed constant displacement, so that the external loads do not perform any work. This means that the outer boundaries of the rift zone are fixed, i.e. do not move during the fracture propagation within it (Fig. 12). The second condition is the constant load, where the load (force, stress, pressure) is prescribed and maintained during the fracture propagation. This means that, for a volcanic-edifice rift zone, the boundaries of the rift zone are flexible and can move outward as the fracture propagates (Fig. 13). Consequently, the generalized force $F$ on the rift-zone boundary does work, denoted by $W_{\mathrm{L}}$, which is equal to the load or force $F$ times generalized displacement $\Delta$, i.e. $W_{\mathrm{L}}=F \times \Delta$. This work can be partly transmitted to the tip of the fracture and help it propagate.

For the constant-load (load-controlled) condition (Fig. 13), the potential energy is defined as:

$\Pi=U_{0}-W_{\mathrm{L}}$

where $U_{0}$ is the strain energy of the host rock of the fracture, here a volcano or a rift zone. From Eq. (17) the energy release rate is:

$G=-\frac{d \Pi}{d A}=-\frac{d\left(U_{0}-W_{\mathrm{L}}\right)}{d A}=\frac{d W_{\mathrm{L}}}{d A}-\frac{d U_{0}}{d A}$

where all the symbols are as defined above. To solve Eq. (20) in terms of loads and displacements, we first note that the work $W_{\mathrm{L}}=F \times \Delta$, and then find a similar expression for the strain energy $U_{0}$ as follows:

$U_{0}=\int_{0}^{\Delta} F d \Delta=\frac{1}{2} F \Delta$

From Eq. (19) we then get:

$\Pi=U_{0}-W_{\mathrm{L}}=1 / 2 F \Delta-F \Delta=-1 / 2 F \Delta=-U_{0}$

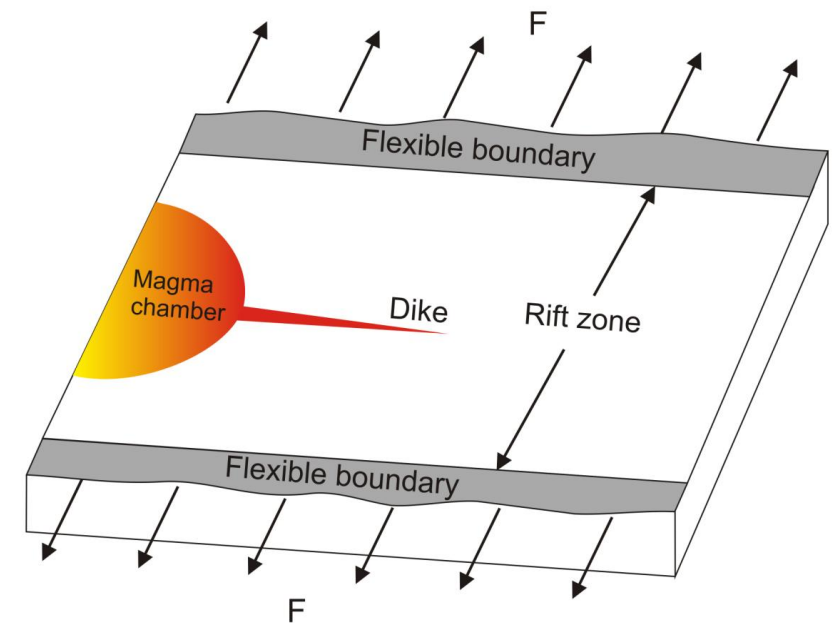

Fig. 13. Dike injected laterally from a magma chamber located in a volcanic edifice associated with a rift-zone segment. A flexible boundary means that the loading is constant during the dike emplacement - i.e. the boundary can move as the dike propagates.

so that, using $A=a \times t$, where $a$ is the fracture length for a tunnel-shaped through crack (Gudmundsson, 2011a) and $t$ is the thickness of the crustal layer hosting the fracture, $G$ becomes:

$$
\begin{aligned}
G & =-\frac{d \Pi}{d A}=-\frac{1}{t}\left(\frac{d\left(-U_{0}\right)}{d a}\right) \\
& =\left(\frac{1}{t} \frac{d}{d a}\left(\frac{F \Delta}{2}\right)\right)=\frac{F}{2 t}\left(\frac{d \Delta}{d a}\right)
\end{aligned}
$$

Since the term on the right-hand side of the last equality sign is positive, it shows that the strain energy of the volcano or rift zone hosting the fracture actually increases as the fracture propagates. This implies that the fracture propagation for the constant-load boundary condition is unstable.

Consider next the boundary condition of constant displacement. Since there is no work done on the boundary of the rift zone or volcano (Fig. 12), it follows that $W_{\mathrm{L}}=0$, in which case, from Eqs. (19) and (21), the total potential energy is:

$\Pi=U_{0}=1 / 2 F \Delta$

i.e. the potential energy (of deformation) is equal to the strain energy, which is equal to half the product of the generalized force $F$ and the generalized displacement $\Delta$. Using again $A=a \times t$, and proceeding as in Eq. (23), we obtain:

$$
\begin{aligned}
G & =-\frac{d \Pi}{d A}=-\frac{1}{t}\left(\frac{d\left(U_{0}\right)}{d a}\right) \\
& =\left(-\frac{1}{t} \frac{\Delta}{2}\left(\frac{d F}{d a}\right)\right)=-\frac{\Delta}{2 t}\left(\frac{d F}{d a}\right)
\end{aligned}
$$

As the term on the right-hand side of the last equality sign is negative, it follows that the strain energy of the volcano 
or rift zone hosting the fracture decreases as the fracture propagates. This implies that the fracture propagation for the constant-displacement boundary condition is stable.

Let us now rewrite and compare the results in Eqs. (23) and (25) so as to understand better the implications for fracture propagation during landslides, caldera collapses, and volcanic eruptions. Force or load $F$ and displacement $\Delta$ are related through the compliance $C$ in a version of Hooke's law, thus:

$$
F=\frac{\Delta}{C}
$$

For constant load boundary conditions, Eq. (23) gives the strain energy release rate $G$ in terms of load $F$ (a constant) and compliance $C$ :

$G=\frac{F}{2 t}\left(\frac{d(F C)}{d a}\right)=\frac{F^{2}}{2 t}\left(\frac{d C}{d a}\right)$

Similarly, for constant displacement boundary conditions, i.e. $\Delta=$ constant, from Eq. (25) we get:

$G=-\frac{\Delta}{2 t}\left(\frac{d\left(\Delta C^{-1}\right)}{d a}\right)=\frac{\Delta^{2}}{2 t C^{2}}\left(\frac{d C}{d a}\right)=\frac{F^{2}}{2 t}\left(\frac{d C}{d a}\right)$

showing that, for the constant load and the constant displacement boundary conditions, we obtain identical expressions (Eqs. 27 and 28) for the strain energy release rate $G$ in terms of generalized load or force $F$ and compliance $C$ for a given fracture growth or extension $d a$. The results also show that, as the fracture grows by $d a$, its compliance increases by $d C$. Since compliance is the reciprocal of stiffness, this means that, during fracture propagation in a volcano, the overall stiffness (Young's modulus, when using stress and strain rather than force and displacement) decreases, i.e. the volcano becomes "softer" or more compliant.

The main results as regards fracture development in volcanoes, based on the present analysis, may be summarized as follows:

1. When the boundaries of a rift zone, or a volcanic edifice as a whole, cannot move during an unrest period and fracture development, the only source of potential energy for the fracture development is the strain energy stored in the volcano/rift zone before fracture propagation starts. The stored strain energy is primarily due to extension across the rift zone, i.e. the stretching related to the extensional forces (such as plate pull for edifices in rift zones located at divergent plate boundaries or spreading for many other volcanoes), to magmachamber inflation as new magma is injected into the chamber during an unrest period, or both. The stored strain energy is transformed into surface energy (which is largely dissipated in the process zone at the tip of the fracture in relation to microcracking or plastic deformation) during fracture propagation. Since no energy is added to the system during the fracture propagation, the strain energy decreases (Eq. 25).

2. When the boundaries of the volcanic edifice or its rift zone can move during the fracture development, there are two principal sources of potential energy for the fracture development: the stored strain energy in the rift zone/volcanic edifice $U_{0}$ and the work $W_{\mathrm{L}}$ done by the external, generalized loading or force. The strain energy stored in the rift zone/volcano decreases as the fracture propagates. However, there is work done on the rift zone/volcano by the external force and this work is partly transformed into energy to drive the fracture propagation.

3. The constant-displacement boundary conditions (Eq. 25) result in stable fracture propagation, i.e. as the fracture propagates the energy (stored strain energy) available to drive the fracture gradually decreases. Thus, other things being equal, constant-displacement boundary conditions favor comparatively small eruptions (for dikes) and landslides or caldera collapses (for shear fractures). By contrast, constant-load boundary conditions (Eq. 23) result in an unstable fracture propagation, i.e. as the fracture propagates, the energy available (strain energy and work) to drive the fracture gradually increases. Generally, therefore, comparatively large eruptions and landslides (and caldera collapses) would be favored by such boundary conditions. These results are, of course, easily extended to shear fractures in general, such as earthquake faults, and imply that, for a given earthquake zone, small earthquakes tend to occur under constant-displacement conditions and larger ones under constant-load conditions - a topic that will be explored elsewhere.

4. During fracture propagation in a rift zone or a volcanic edifice, the energy release rate $G$ can increase, remain constant, or decrease, depending on the type of boundary conditions applied and the fracture geometry. Thus, the boundary conditions partly determine the fate of the fracture, which is also controlled by the layering of the volcanic edifice, i.e. the edifice strength.

For fractures (dikes, inclined sheets, faults) to develop in a volcano or its rift zone(s), energy input is needed. For longer fractures, more energy is needed than for short fractures (Mohajeri and Gudmundsson, 2012). As indicated, the available energy sources, however, depend on the boundary conditions at the time of fracture initiation and propagation. More specifically, Eqs. (19) and (20), and the signs for $W_{\mathrm{L}}$, and $U_{0}$ in Eq. (19), can be explained in more detail as follows. When the displacement is fixed, the boundaries of, say, a volcanotectonic rift zone cannot move when a dike or other fractures are emplaced or slip within that zone (Fig. 12). This means that the only energy available to overcome the surface 
energy of the rock $W_{\mathrm{s}}$ during fracture propagation is the energy stored as strain energy in the host rock of the fracture (due to magma-chamber inflation and/or tensile strain related to extension across the rift zone) before the fracture starts to propagate. Thus, for a fixed displacement, the total potential energy available for driving the fracture $\Pi$ is equal to the strain energy $U_{0}$ stored in the host rock, hence Eq. (24). As the fracture propagates, the strain energy available to drive the propagation gradually decreases, so that, for fixed displacement, the fracture propagation is stable.

By contrast, for the constant-load conditions the boundaries of the rift zone are flexible, i.e. can move when a dike or other fractures are emplaced or slip within the zone (Fig. 13). In this case, the potential energy increases as the fracture propagates or grows. This follows because, when the load is kept constant during the fracture propagation, the boundary of the rift zone adjacent to the fracture does work, i.e. the boundary becomes displaced in a direction away from the fracture. As indicated above, the work done by the generalized load is $W_{\mathrm{L}}=F \times \Delta$, and the strain energy is (Eq. 21) $U_{0}=1 / 2 F \Delta$. From Eqs. (22) and (23), it then follows that, as the fracture grows, the energy available to drive the growth increases, which means that the fracture propagation is unstable.

\section{Application}

As an exercise in application, we consider first a magma chamber that is totally molten, as is commonly assumed when modeling chambers beneath major volcanic edifices. The "Mogi model" assumes the magma chamber to be spherical. Below, we will briefly consider a spherical chamber. However, sill-like chambers are presumably the most common in the world, and are the geometries often inferred from seismic and other geophysical measurements for active chambers, as well as for many fossil chambers, or plutons (Gudmundsson, 1990; Annen and Sparks, 2002; Gudmundsson, 2006; Kavanagh et al., 2006; Menand et al., 2010; Menand, 2011). Thus, the focus is on sill-like magma chambers.

The maximum diameters of active calderas on Earth range from $1.6 \mathrm{~km}$ to about $80 \mathrm{~km}$, the largest being multiple and geometrically complex. For comparison, the maximum diameters of Quaternary calderas range from about $1.6 \mathrm{~km}$ to about $50 \mathrm{~km}$ (Lipman, 2000; Krassilnikov and Head, 2004; Gudmundsson, 2008). There is a difference in caldera size between basaltic edifices and stratovolcanoes. In active basaltic edifices, the mean maximum caldera diameter is 6$7 \mathrm{~km}$, whereas in stratovolcanoes the mean maximum caldera diameter is $18-19 \mathrm{~km}$ (Radebaugh et al., 2001), suggesting greater energy available to form typical calderas in stratovolcanoes. For calderas, the collapse diameter is normally similar, or somewhat smaller, than the diameter of the associated shallow magma chamber (Gudmundsson, 2008).
Using common dimensions of calderas formed in single collapses, as well as studies of active and fossil magma chambers, typical dimensions of a sill-like chamber associated with a major volcanic edifice would be a diameter of $8 \mathrm{~km}$ and a thickness of about $2.5 \mathrm{~km}$. The chamber volume would then be about $167 \mathrm{~km}^{3}$. This is well within the range of estimated magma-chamber volumes, generally between $5 \mathrm{~km}^{3}$ and $500 \mathrm{~km}^{3}$ (Chester, 1993). For a spherical chamber, rather than the sill-like used here, the chamber diameters corresponding to volumes of $5-500 \mathrm{~km}^{3}$ would be from $2 \mathrm{~km}$ to $10 \mathrm{~km}$. For the largest eruptions, producing in excess of thousand cubic kilometers of pyroclastic materials, the magma chambers may have been even larger than this possibly more than $1000 \mathrm{~km}^{3}$.

The magma-chamber volume of $167 \mathrm{~km}^{3}$ is thus much less than the likely maximum volume that crustal magma chambers can have. Very large magma chambers, say 500$1000 \mathrm{~km}^{3}$, are presumably rare, whereas smaller magma chambers, say $20-200 \mathrm{~km}^{3}$, are much more common. This follows from general probability considerations of the size distributions of eruptive materials in single eruptions, as well as from the size distributions of plutons and calderas (Sibbett, 1988; Marsh, 1989; Radebaugh et al., 2001; Gudmundsson, 2008). The size distributions of all these objects follow negative exponential laws, and many follow power laws. This means that most of the objects are small, whereas a few ones are very large (e.g. Mohajeri and Gudmundsson, 2012). There is a cutoff size, however, in that very small magma chambers, while presumably formed frequently, tend to have very short active lifetimes. They solidify rapidly and soon cease to act as magma chambers. Overall, chambers between $50 \mathrm{~km}^{3}$ and $200 \mathrm{~km}^{3}$ are likely to be common, and the value $167 \mathrm{~km}^{3}\left(1.67 \times 10^{11} \mathrm{~m}^{3}\right)$ is well within that range.

To calculate the strain energy in the volcano due to the magma-chamber expansion (inflation) prior to rupture and dike injection, we must first calculate the volume of magma received by the chamber, using Eq. (8). A typical compressibility for basaltic magma is $\beta_{\mathrm{m}}=1.25 \times 10^{-10} \mathrm{~Pa}^{-1}$, and that for the magma-chamber host rock is $\beta_{\mathrm{c}}=2.94 \times$ $10^{-11} \mathrm{~Pa}^{-1}$ (Gudmundsson, 2006). For a totally molten magma chamber, as assumed here, $\gamma=1.0$. The excess pressure at magma-chamber rupture may be regarded as roughly equal to the in-situ tensile strength of the host rock, a typical value of which is $3 \mathrm{MPa}$ (Gudmundsson, 2011a). Using these values and the above estimate for the magma-chamber volume, $V_{\mathrm{c}}=1.67 \times 10^{11} \mathrm{~m}^{3}$, we obtain the magma volume $V_{\mathrm{re}}$ received (from the deeper source/reservoir) by the shallow magma chamber as:

$V_{\mathrm{re}}=p_{\mathrm{e}} \gamma\left(\beta_{\mathrm{m}}+\beta_{\mathrm{c}}\right) V_{\mathrm{c}}=7.7 \times 10^{7} \mathrm{~m}^{3}$

We shall now calculate the strain energy in the volcano due to the added magma and magma-chamber inflation in two ways: first, using strain-nucleus (corresponding to a spherical chamber), and second using a sill-like magma chamber. 
Consider first the formula for the magma-chamber volume. For a general ellipsoid, the volume $V_{\mathrm{f}}$ is:

$$
V_{\mathrm{f}}=\frac{4}{3} \pi a b c
$$

where $a, b, c$ are the semiaxes of the ellipsoid. For a spherical chamber $a=b=c$, and this reduces to the well-known formula $V_{\mathrm{f}}=4 / 3 \pi a^{3}$. For a volume $V_{\mathrm{f}}=167 \mathrm{~km}^{3}$, for a spherical chamber we obtain the radius $a=3.4 \mathrm{~km}$. Using this radius and the values used above for Eq. (29), we obtain the strain energy from Eq. (9) as $U_{\mathrm{n}}=1.17 \times 10^{17} \mathrm{~J}$ or about $0.12 \mathrm{EJ}$. This is similar to the energy released in a magnitude 8 earthquake (cf. earthquake.usgs.gov). Of course, the chamber here is no longer with a very small radius in comparison with its depth below the surface (Fig. 11) - which was the assumption in Eq. (8) that was used in Eq. (9). Also, totally molten chambers of radius $3.4 \mathrm{~km}$ are probably not common, suggesting that this is not a realistic approach to strain-energy estimates for most magma chambers. Rather, this exercise is mainly meant for comparison with the more realistic model of a sill-like chamber below.

For the sill-like magma chamber, the volume is assumed the same as above, namely $167 \mathrm{~km}^{3}$. If the magma chamber has a radius $a$ and if $u$ is the vertical displacement ("uplift") of its roof during the inflation, then Eq. (30) may be rewritten in the form:

$$
V_{\mathrm{f}}=\frac{4}{3} \pi a^{2} u
$$

Notice that for a real magma chamber, the total opening displacement may be the uplift of the roof, i.e. there may not necessarily be any downward displacement of the lower boundary (the bottom) of the magma chamber. That would not, however, change the results of the present analysis. The displacement of the roof of the sill-like magma chamber is equal to half the displacement of a penny-shaped fracture subject to internal magmatic excess pressure $p_{\mathrm{e}}$ and is given by (Sneddon and Lowengrub, 1969; Gudmundsson, 2011a):

$u=\frac{4 p_{\mathrm{e}}\left(1-v^{2}\right) a}{\pi E}$

where $E$ is Young's modulus and $v$ is Poisson's ratio. Combining Eqs. (31) and (32) and referring to the volume increase due to the inflation as $\Delta V_{\mathrm{c}}$ (Eq. 11), we get:

$$
\Delta V_{\mathrm{c}}=\frac{4}{3} \pi a^{2}\left[\frac{4\left(1-v^{2}\right) p_{\mathrm{e}} a}{\pi E}\right]=\frac{16\left(1-v^{2}\right) p_{\mathrm{e}} a^{3}}{3 E}
$$

From Eq. (11) we know that the total work in expanding the magma chamber is equal to $p_{\mathrm{e}} \times \Delta V_{\mathrm{c}}$ and has the units of $\mathrm{N} \mathrm{m}$. But we also know that the total strain energy in a body (in equilibrium) under the action of forces is equal to half the work done by the forces through the associated displacements, from the unstrained to the strained state (e.g. Love,
1927; Jaeger and Cook, 1979). This is indicated in Eq. (24). It follows that the strain energy of the volcano is half the value of Eq. (11). Substituting Eq. (33) for $\Delta V_{\mathrm{c}}$ in Eq. (11) and multiplying by $1 / 2$, we get the strain energy $U_{0}$ due to the inflation of the magma chamber in the volcano as:

$U_{0}=\frac{8\left(1-v^{2}\right) p_{\mathrm{e}}^{2} a^{3}}{3 E}$

where all the symbols are as defined above. Effectively, this is the strain energy solely due to the expansion of the magma chamber. As discussed earlier and below, there are other factors that may contribute to the total strain energy in the volcano or rift zone at the time of magma-chamber rupture and feeder-dike emplacement.

Let us now apply these results to a typical volcano. We can calculate the strain energy directly from Eq. (33) using only the assumed excess pressure $p_{\mathrm{e}}$ of $3 \mathrm{MPa}$. Alternatively, we can use an estimated vertical surface displacement above the sill-like magma chamber during deflation and then calculate the associated strain energy in the volcano from Eqs. (11), (31) and (32). Let us first use Eq. (33). For a sill-like shallow magma chamber at, say, $3 \mathrm{~km}$ depth, and with dimensions indicated above, i.e. volume of $167 \mathrm{~km}^{3}$ and diameter of $8 \mathrm{~km}$, then, from Eq. (33), the strain energy is:

$$
\begin{aligned}
U_{0} & =\frac{8\left(1-v^{2}\right) p_{\mathrm{e}}^{2} a^{3}}{3 E} \\
& =\frac{8\left(1-0.25^{2}\right)\left(3 \times 10^{6}\right)^{2}(4000)^{3}}{3 \times 2 \times 10^{10}}=7.2 \times 10^{13} \mathrm{~J}
\end{aligned}
$$

The second method is to combine Eqs. (11), (31) and (32) to calculate the strain energy from the measured vertical displacement of the upper boundary or roof of the magma chamber. Using the same values as in Eq. (35) for the magmachamber size and elastic properties, we use a common value of maximum uplift of the volcano surface as $1 \mathrm{~m}$. Similar, or larger, surface uplifts have been observed in many volcanoes prior to eruptions (e.g. hvo.wr.usgs.gov). While the displacement of the roof and floor of a sill-like chamber may be considerably larger than the measured surface uplift, which depends much on the mechanical layering of the volcano (e.g. Gudmundsson, 2003, 2006; Masterlark, 2007), we shall here use $1 \mathrm{~m}$ as the reference displacement value for the roof. From Eq. (31) we obtain the volume of the chamber expansion as $6.7 \times 10^{7} \mathrm{~m}^{3}$. From Eq. (32) the excess pressure needed to generate $1 \mathrm{~m}$ uplift is $p_{\mathrm{e}}=4.1 \mathrm{MPa}$, or somewhat larger than the assumed value of $3 \mathrm{MPa}$. Using these values for the volume and excess pressure, and taking the strain energy as half the work done during the inflation, Eq. (11) gives the strain energy due to the inflation as about $1.35 \times 10^{14} \mathrm{~J}$. This value differs from the one in Eq. (35) by the ratio of the excess pressures used (4.1 MPa over $3 \mathrm{MPa}$ ) squared. These results indicate that the change in strain energy related to a typical inflation period in a volcano prior to an eruption is of the order of $10^{14} \mathrm{~J}$. 
Let us now compare this strain energy with the surface energy needed to form a feeder dike. Consider a feeder dike that is $2-4 \mathrm{~km}$ long (strike dimension) and $2 \mathrm{~km}$ tall (dip dimension). If the estimated energy release rate for a typical dike of about $2 \times 10^{7} \mathrm{~J} \mathrm{~m}^{-2}$ (Gudmundsson, 2009, 2011a) is multiplied by the area of the feeder dike, we obtain the total strain energy needed to form the dike (to overcome the surface energy) as $1-2 \times 10^{14} \mathrm{~J}$. These results indicate that the strain energy needed to form the dike-fracture, in a typical small eruption in a basaltic edifice or a stratovolcano, is of the same order of magnitude as the strain energy generated by a typical magma-chamber inflation prior to the eruption.

As indicated above, there are, in addition to inflation, other sources of strain energy that may contribute to feeder-dike formation and the associated eruption. One is already discussed, namely loading of the volcano or rift zone prior to eruption through external loads. These include the tensile forces associated with divergent plate movements (plate pull), for rift zones at plate boundaries, and the forces associated with volcano spreading for many volcanoes (e.g. Gudmundsson, 1990, 2006; Costa et al., 2011). For example, if the volcano is located within a larger rift zone at a plate boundary, the strain energy stored inside and in the vicinity of the volcano due to the plate-pull forces may be of the same order of magnitude (or larger, depending on the volume of the rift zone) as the strain energy due to magma-chamber inflation. The dike itself also has overpressure, which depends partly on the excess pressure in the source chamber and partly on the density difference between the magma and the host rock, i.e. buoyancy effects (e.g. Spence et al., 1987; Gudmundsson, 1990; Costa et al., 2009; Taisne et al., 2011). The load due to the overpressure generates strain energy in the surrounding host rock. Different strain energies due to magma-chamber inflation are also obtained when any of the following three parameters changes (Eq. 35): Young's modulus $(E)$, excess pressure $\left(p_{\mathrm{e}}\right)$, and magma-chamber size $(a)$. These can all vary considerably, whereas Poisson's ratio (v) is essentially constant (Gudmundsson, 2011a).

Based on the models proposed here, stratovolcanoes are mechanically stronger than basaltic edifices. And this greater strength is largely due to typical stratovolcanoes being composed of rock layers with more widely different mechanical properties than those layers that constitute typical basaltic edifices. Because of their greater strengths, many stratovolcanoes are likely to be able to store considerably greater strain energies before eruptions than typical basaltic edifices. This may contribute to a typical stratovolcano being able to "squeeze out" a larger proportion of the magma in its chamber during an eruption than a typical basaltic edifice and produce larger collapse calderas.

\section{Discussion}

There are many factors that may contribute to the differences in geometry and failure frequencies of stratovolcanoes and basaltic edifices (shield volcanoes). These need to be considered when assessing the importance of the present model in explaining failure frequencies of these volcano types. One reason for, say, not getting an accurate view of the frequencies of vertical and lateral collapses is that the scars may be comparatively quickly buried with new eruptive materials. On reflection, however, this is unlikely to cause a large bias in the assessment of relative failure frequencies in stratovolcanoes and basaltic edifices. Both stratovolcanoes and basaltic edifices tend to "heal their scars", yet the scars are normally visible for a considerable time after the event. For example, following a caldera collapse in many stratovolcanoes, a new edifice builds up either somewhere near the center of the caldera or at one particular location along the ring fault (e.g. Newhall and Dzurisin, 1988; Wood and Kienle, 1990; Scarth and Tanguy, 2001; Francis and Oppenheimer, 2003; Pichler and Pichler, 2007). The greater part, or the whole, of the ring fault is thus easily recognizable even after the new edifice is fully formed.

Also, if, as suggested here, the eruption frequency in a typical stratovolcano is considerably less than that in a typical basaltic edifice, then the scars from lateral and vertical collapses might be expected to be visible over longer periods of time in stratovolcanoes than in the basaltic edifices. We might therefore expect any bias, if it existed, to exaggerate the frequency of collapses in stratovolcanoes in comparison with basaltic edifices. The lifetimes of the volcanoes may also possibly affect the number of inferred collapses. For example, if large basaltic edifices would live (be active) longer than large stratovolcanoes, this might affect the number of visible scars or collapse structures observed on these volcano types. But even Mauna Loa, the largest basaltic edifice on Earth, is less than million years old (hvo.wr.usgs.gov/maunaloa), which is similar to, or less than, the lifetimes of many major stratovolcanoes. And, in addition, because of its high eruption frequency, Mauna Loa is almost entirely covered with lava flows younger than about $4000 \mathrm{yr}$ (Frank, 2003), thereby supporting the comparatively rapid healing of scars on basaltic edifices, as suggested above.

Another point sometimes raised, and indicated earlier, is that because the average viscosity of magmas and lavas issued from stratovolcanoes is higher than that of lavas from basaltic edifices, the stratovolcanoes tend to develop steeper slopes. It is of course clear that the viscosities of intermediate and acid or generally felsic lava flows, which constitute significant parts of many stratovolcanoes, are much greater than those of typical tholeities, which constitute the greater part of many basaltic edifices (Murase and McBirney, 1973; Kilburn, 2000; Spera, 2000). The high-viscosity lavas can come to a halt more easily on steeper slopes than low-viscosity 
lavas (although lava thicknesses and cooling rates are also factors). However, to maintain the steep slopes of a stratovolcano, whether formed by high-viscosity lava flows or pyroclastics and sedimentary rocks, the condition for large-scale failure must be met only rarely. Why those conditions are apparently so rarely satisfied in stratovolcanoes needs to be explained, and one such explanation is their great mechanical strength - as suggested here.

The slope angle also affects the probability of generating landslides, i.e. shear failure (e.g. Scheidegger, 1970; Afrouz, 1992; Wyllie and Mah, 2004; Apuani et al., 2005). It might be argued that this factor should thus also be considered in the present analysis. However, the slope angle is already included in any proper stress analysis for shear failure, because it affects the normal and shear stresses on the potential failure (fault) plane (e.g. Gudmundsson, 2011a). For shallow surface landslides, as are common on volcanoes, the steeper the slope, normally the greater the chance of shear failure. It then follows that the likelihood of shear failure should be greater, other things being equal, in stratovolcanoes than in basaltic edifices. Since the opposite appears to be the case, we are again facing the fact that stratovolcanoes appear much stronger than basaltic edifices, a fact that must be explained.

The mechanical ideas and models presented in this paper constitute one such explanation. For landslides, the main mechanical point explored here is that the tendency to shearfracture arrest is much greater in a stratovolcano than in a basaltic edifice (Fig. 14). While there are clearly other factors that contribute to the probability of landslide formation in volcanic edifices, the results presented here indicate that the tendency to arrest is one of the main reasons for the difference in large-landslide frequencies between stratovolcanoes and basaltic edifices. The same conclusions apply to the formation of shear fractures, faults, in volcanic edifices in general, and as regards the formation or reactivation of collapse calderas in particular.

The conditions that must be satisfied so that a dike is able to propagate to the surface of a volcano have received much attention in recent years. Many of the stress-field models are discussed by Gudmundsson (2006), whereas models focusing more on materials-science aspects and fracture mechanics are presented by Gudmundsson $(2009,2011 b)$. Some papers explicitly deal with the effects of overpressure-related variation in dike aperture and external loading on magma flow during eruptions (Costa et al., 2009, 2011). Other recent papers on this and related topics include Canon-Tapia et al. (2006), Menand et al. (2010), Geshi et al. (2010, 2012), Taisne et al. (2011), and Maccaferri et al. (2010, 2011). A detailed statistical summary of "failed eruptions" (mostly arrested dikes) is provided by Moran et al. (2011).

During unrest periods with magma-chamber inflation and/or loading due to tensile stresses associated with riftzone extension, potential mechanical energy is stored in the volcanic edifice or rift zone. Part of this energy is stored as internal strain energy. When the outer boundaries
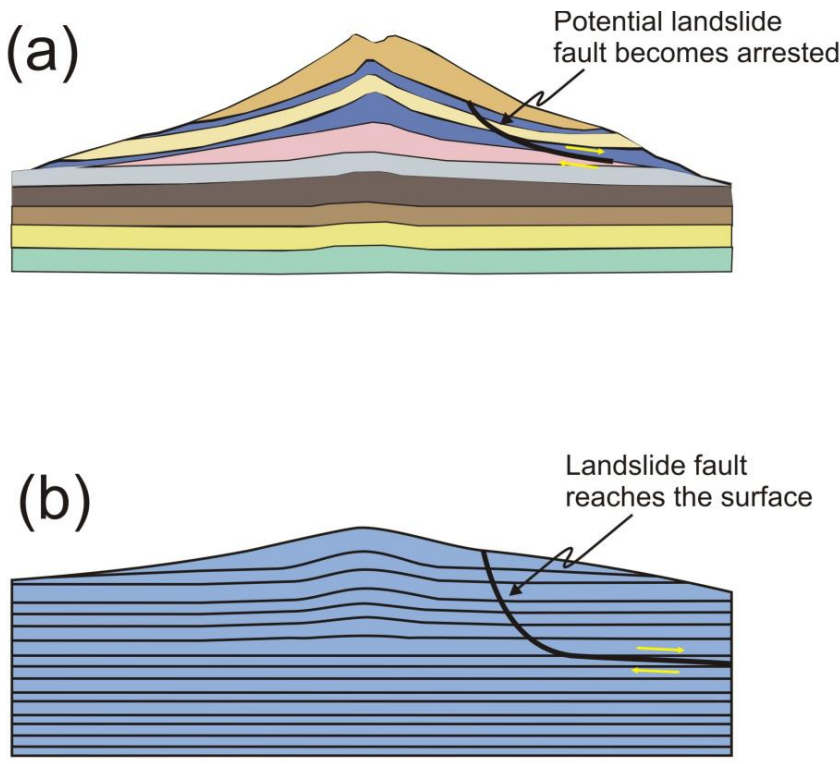

Fig. 14. For a large landslide to occur in a volcanic edifice, the shear-fracture (the landslide fault or slip surface) must reach the surface along the slopes of the volcano; if the fracture becomes arrested, no major landslide can occur. The tendency for a potential landslide fault to become arrested is normally greater in a stratovolcano (a) than in a basaltic edifice (b).

of the edifice/rift zone are flexible and subject to generalized force, additional energy is available to drive the fracture propagation as the work done by the generalized force. The size of the resulting fracture and, by implication, the resulting eruption (other things being equal) thus depends on the boundary conditions operating during the eruption. Small eruptions/collapses tend to occur under constantdisplacement boundary conditions (Eq. 25), while larger eruptions/collapses rather occur under constant-load boundary conditions (Eq. 23).

As indicated above, there are many factors in addition to the magma-chamber inflation that may contribute to the strain energy stored in a volcano before eruption. These need to be considered in a further development of the ideas presented here. One factor, however, is worth emphasizing in this context, namely the effects of differences in average Young's moduli and mechanical strength between stratovolcanoes and basaltic edifices. Since the average Young's modulus of a part of a stratovolcano is normally less than that of a similarly sized part of a basaltic edifice, while at the same time the stratovolcano is mechanically stronger, the stratovolcano would normally be able to store more strain energy before eruption than a basaltic edifice. This is probably one reason as to why eruptions in stratovolcanoes, when they happen, tend to be more powerful and can generate larger calderas than those in basaltic edifices.

The use of Eqs. (11), (31), (32) and (33) for calculating the strain-energy change associated with magma-chamber 
inflation is most appropriate for a sill-like chamber that is of a depth below the surface that is comparable to the diameter of the chamber. If the depth is much less than the diameter of the chamber, as is assumed in the calculations here, then the magmatic excess pressure in the chamber may result in bending of the layers above the chamber (Pollard and Johnson, 1973; Gudmundsson, 1990). Such a bending may eventually result in a laccolith shape of the chamber (Pollard and Johnson, 1973). It is well known, however, that many comparatively shallow sills do not generate such bending (Gudmundsson, 2011b). For the present purpose of orderof-magnitude calculations, the models used are sufficiently accurate, but a future development of the ideas presented here will take into account possible crustal bending and stress variations within the edifices and their effects on the strainenergy storage before eruption.

Knowing the condition for extension-fracture (dike, inclined sheet, and sill) propagation and arrest in volcanoes is of fundamental importance for understanding how volcanoes work and the associated hazards. During unrest periods with earthquakes and inferred dike injections, it is very important to be able to forecast whether or not the injected dike is likely to reach the surface. If the dike is most likely to become arrested, the result is a "failed eruption", and its propagation path and eventual arrest is of interest and importance primarily to the volcanological community. If, however, the dike is unlikely to become arrested (i.e. is most likely to reach the surface), the results have implications for all the properties and people and their means of transportation (including air transportation) that may be affected by that eruption.

Similarly, understanding the conditions for shear-fracture propagation and arrest is of fundamental importance for realistic forecasting of vertical (caldera) and lateral (landslide) collapses. Here the societal implications are often even greater than those associated with ordinary dike propagation to the surface. Large landslides in ocean islands may generate tsunamis that can have devastating effects far away from the volcano itself. And the largest collapse-caldera eruptions are, together with meteoritic impacts, presumably the greatest natural hazards to life on our planet.

\section{Conclusions}

Because a stratovolcano is composed of layers with widely different elastic properties (Fig. 6), it is tougher than a basaltic edifice. The high toughness of a typical stratovolcano is one principal reason why dike-fed eruptions are rarer in stratovolcanoes than in basaltic edifices. Similarly, based on available data, lateral and vertical collapses also appear to be less frequent in stratovolcanoes than in basaltic edifices, which, again, may be partly explained by the comparatively high toughness of typical stratovolcanoes. I propose that stratovolcanoes become strong because they function as high-toughness composite structures made of layers that encourage fracture deflection and arrest (Figs. 1-6). The strain energy required to propagate a fracture for a given distance (and through many layers) in a stratovolcano is therefore normally much larger than that required to propagate a fracture an equal distance in a basaltic edifice. In other words, strain energy that is sufficiently large to propagate a feeder dike, a caldera fault, or a landslide fault through many layers and to the surface in a basaltic edifice is commonly too small to propagate a similar fracture to the surface in a stratovolcano.

The potential energy considerations in this paper suggest that the boundary conditions that operate during fracture propagation in a volcanic edifice or rift zone may partly control the size of the resulting eruption, landslide, or caldera collapse (and, by implication, the sizes of earthquakes). The constant-displacement boundary conditions favor stable fracture propagation and comparatively small eruptions, landslides or caldera collapses. By contrast, the constant-load boundary conditions favor unstable fracture propagation and comparatively large eruptions, landslides, and caldera collapses.

Acknowledgements. I thank Nahid Mohajeri for improving the illustrations and for helpful suggestions. I also thank Valerio Acocella, Shigekazu Kusumoto, and Alessandro Tibaldi for very helpful review comments.

Edited by: A. Costa

Reviewed by: A. Tibaldi and one anonymous referee

\section{References}

Acosta, J., Uchupi, E., Munoz, A., Herranz, P., Palomo, C., and Ballesteros, M.: Geological evolution of the Canary Islands of Lanzarote, Fuerteventura, Gran Canaria and La Gomera and comparison of landslides at these islands and those of Tenerife, La Palma and El Hierro, Mar. Geophys. Res., 26, 77-79, 2005.

Afrouz, A. A.: Practical Handbook of Rock Mass Classification Systems and Modes of Ground Failure, CRC Press, London, 1992.

Anderson, T. L.: Fracture Mechanics: Fundmentals and Applications, 3rd Edn., Taylor \& Francis, Londonm, 2005.

Annen, C. and Sparks, R. S. J.: Effects of repetitive emplacement of basaltic intrusions on the thermal evolution and melt generation in the crust, Earth Planet. Sci. Lett., 203, 975-955, 2002.

Apuani, T., Corazzato, C., Cancelli, A., and Tibaldi, A.: Stability of a collapsing volcano (Stromboli, Italy): Limit equilibrium analysis and numerical modelling, J. Volcanol. Geoth. Res., 144, 191210, 2005.

Atkins, P. and dePaula, J.: Physical Chemistry, 9th Edn., Oxford University Press, Oxford, 2010.

Beget, J. E. and Kienle, J.: Cyclic formation of debris avalanches at mount St Augustine volcano, Nature, 356, 701-704, 1992.

Bell, F. G.: Engineering properties of rocks, 4th Edn., Oxford, Blackwell, 2000. 
Blundell, S. J. and Blundell, K. M.: Concepts in Thermal Physics, 2nd Edn., Oxford University Press, Oxford, 2010.

Boudon, G., Le Friant, A., Komorowski, J. C., Deplus, C., and Semet, M. P.: Volcano flank instability in the lesser Antilles arc: diversity of scale, processes, and temporal recurrence, J. Geophys. Res., 112, B08205, doi:10.1029/2006JB004674, 2007.

Broberg, K. B.: Cracks and fracture, Academic Press, New York, 1999.

Canon-Tapia, E. and Merle, O.: Dyke nucleation and early growth from pressurized magma chambers: insights from analogue models, J. Volcanol. Geoth. Res., 158, 207-220, 2006.

Casagli, N., Tibaldi, A., Merri, A., Del Ventisette, C., Apuani, T., Guerri, L., Fortuny-Guasch, J., and Tarchi, D.: Deformation of Stromboli Volcano (Italy) during the 2007 eruption revealed by radar interferometry, numerical modelling and structural geological field data, J. Volcanol. Geoth. Res., 182, 182-200, 2009.

Chester, D.: Volcanoes and Society, Edward Arnold, London, 1993.

Costa, A., Sparks, R. S. J., Macedonio, G., and Melnik, O.: Effects of wall-rock elasticity on magma flow in dykes during explosive eruptions, Earth Planet. Sci. Lett., 288, 455-462, 2009.

Costa, A., Gottsmann, J., Melnik, O., and Sparks, R. S. J.: A stresscontrolled mechanism for the intensity of very large magnitude explosive eruptions, Earth Planet. Sci. Lett., 310, 161-166, 2011.

Francis, P. and Oppenheimer, C.: Volcanoes, 2nd Edn., Oxford University Press, Oxford, 536 pp., 2003.

Frank, F.: Handbook of the 1350 active volcanoes of the world, Thun, Switzerland, Otto Verlag, 192 pp., 2003 (in German).

Geshi, N., Kusumoto, S., and Gudmundsson, A.: Geometric difference between non-feeders and feeder dikes, Geology, 38, 195198, 2010.

Geshi, N., Kusumoto, S., and Gudmundsson, A.: Effects of mechanical layering of host rocks on dike growth and arrest, J. Volcanol. Geoth. Res., 223, 74-82, 2012.

Geyer, A. and Marti, J.: The new worldwide collapse caldera database (CCDB): A tool for studying and understanding caldera processes, J. Volcanol. Geoth. Res., 175, 334-354, 2008.

Gudmundsson, A.: Emplacement of dikes, sills and crustal magma chambers at divergent plate boundaries, Tectonophysics, 176, 257-275, 1990.

Gudmundsson, A.: Surface stresses associated with arrested dykes in rift zones, Bull. Volcanol., 65, 606-619, 2003.

Gudmundsson, A.: How local stresses control magma-chamber ruptures, dyke injections, and eruptions in composite volcanoes, Earth-Sci. Rev., 79, 1-31, 2006.

Gudmundsson, A.: Magma-chamber geometry, fluid transport, local stresses and rock behavior during collapse caldera formation, in: Caldera Volcanism, edited by: Gottsmann, J. and Marti, J., Developments in Volcanology 10, Elsevier, Amsterdam, 313-349, 2008.

Gudmundsson, A.: Toughness and failure of volcanic edifices, Tectonophysics, 471, 27-35, 2009.

Gudmundsson, A.: Rock fractures in geological processes, Cambridge University Press, Cambridge, 2011a.

Gudmundsson, A.: Deflection of dykes into sills at discontinuities and magma-chamber formation, Tectonophysics, 500, 5064, 2011b.

He, M. Y. and Huchinson, J. W.: Crack deflection at an interface between dissimilar elastic materials, Int. J. Solids Struct., 25, 1053 1067, 1989.
Hutchinson, J. W.: Stresses and failure modes in thin films and multilayers, Lecture Notes, Technical University of Denmark, Lyngby, 1996.

Jaeger, J. C. and Cook, N. G. W.: Fundamentals of Rock Mechanics, 3rd Edn., Methuen, London, 1979.

Kavanagh, J. L., Menand, T., and Sparks, R. S. J.: An experimental investigation of sill formation and propagation in layered elastic media, Earth Planet. Sci. Lett., 245, 799-813, 2006.

Kilburn, C. J.: Lava flows and flow fields, in: Encyclopedia of Volcanoes, edited by: Sigurdsson, H., Academic Press, New York, 291-305, 2000.

Kim, J.-W., Bhowmick, S., Hermann, I., and Lawn, B. R.: Transverse fracture of brittle bilayers: relevance to failure of allceramic dental crowns, J. Biomedical Materials Res., 79B, 5865,2006

Krassilnikov, A. S. and Head, J. W.: Calderas on Venus and Earth: comparison and models of formation, Lunar Planet. Sci., 35 1531, 2004.

Kusumoto, S. and Gudmundsson, A.: Magma-chamber volume changes associated with ring-fault initiation using a finite-sphere model: Application to the Aira caldera, Japan, Tectonophysics, 471, 58-66, 2009.

Lee, J. J.-W., Lloyd, I. K., Chai, H., Jung, Y.-G., and Lawn, B. R.: Arrest, deflection, penetration and reinitiation of cracks in brittle layers across adhesive interlayers, Acta Materials, 55, 58595866, 2007.

Lipman, P.: Calderas, in: Encyclopedia of Volcanoes, edited by: Sigurdsson, H., Academic Press, San Francisco, 643-662, 2000.

Lockwood, J. P. and Hazlett, R. W.: Volcanoes: Global Perspectives, Wiley-Blackwell, Oxford, 2010.

Love, A. E. H.: A Treatise on the Mathematical Theory of Elasticity, Dover, New York, 1927.

Maccaferri, F., Bonafede, M., and Rivalta, E.: A numerical model of dyke propagation in layered elastic media, Geophys. J. Int., 180, 1107-1123, 2010.

Maccaferri, F., Bonafede, M., and Rivalta, E.: A quantitative study of the mechanisms governing dike propagation, dike arrest and sill formation, J. Volcanol. Geoth. Res., 208, 39-50, 2011.

Marsh, B. D.: Magma chambers, Ann. Rev. Earth Planet. Sci., 17, 439-474, 1989.

Masterlark, T.: Magma intrusion and deformation predictions: sensitivities to the Mogi assumptions, J. Geophys. Res., 112, B06419, doi:10.1029/2006JB004860, 2007.

Menand, T.: Physical controls and depth of emplacement of igneous bodies: a review, Tectonophysics, 500, 11-19, 2011.

Menand, T., Daniels, K. A., and Benghiat, P.: Dyke propagation and sill formation in a compressive tectonic environment, J. Geophys. Res., 115, B08201, doi:10.1029/2009JB006791, 2010.

Mogi, K.: Relations between eruptions of various volcanoes and the deformations of the ground surfaces around them, Bull. Earthq. Res. Inst., 36, 99-134, 1958.

Mohajeri, N. and Gudmundsson, A.: Entropies and scaling exponents of street and fracture networks, Entropy, 14, 800-833, 2012.

Moore, J. G., Normark, W. R., and Holcomb, R. T.: Giant Hawaiian landslides, Ann. Rev. Earth Planet. Sci., 22, 119-144, 1994.

Moran, S. C., Newhall, C., and Roman, D. C.: Failed magmatic eruptions: late-stage cessation of magma ascent, Bull. Volcanol., $73,115-122,2011$. 
Murase, T. and McBirney, A. R.: Properties of some common igneous rocks and their melts at high temperatures, Geol. Soc. Am. Bull., 84, 3563-3592, 1973.

Nakada, S., Uto, K., Sakuma, S., Eichelberger, J. C., and Shimizu, H.: Scientific results of the conduit drilling in the Unzen Scientific Drilling Project (USDP), Sci. Drilling, 1, 18-22, 2005.

Newhall, C. G. and Dzurisin, D.: Historical unrest of large calderas of the world, US Geol. Survey Bulletin 1855, Reston, VA, 1988.

Oehler, J. F., de Vries, B. V. W., and Labazuy, P.: Landslides and spreading of oceanic hot-spot and arc shield volcanoes on low strength layers (LSLs): an analogue modelling approach, J. Volcanol. Geoth. Res., 144, 169-189, 2005.

Pichler, H. and Pichler, T.: The Volcanic Areas of the Earth, Elsevier, München, 2007 (in German).

Pollard, D. D. and Johnson, A. M.: Mechanics of growth of some laccolithic intrusions in the Henry Mountains, Utah, II, Bending and failure of overburden layers and sill formation, Tectonophysics, 18, 311-354, 1973.

Radebaugh, J., Keszthelyi, L. P., McEwen, A. S., Turtle, E. P., Jaeger, W., and Milazzo, M.: Paterae on Io: a new type of volcanic caldera?, J. Geophys. Res., 106, 33005-33020, 2001.

Reid, M.: Massive collapse of volcano edifices triggered by hydrothermal pressurization, Geology, 32, 373-376, 2004.

Rosi, M., Papale, P., Lupi, L., and Stoppato, M.: Volcanoes: Buffalo, Firefly Books, 2003.

Sanford, R. J.: Principles of Fracture Mechanics, Prentice Hall, New York, 2003.

Scarth, A. and Tanguy, J. C.: Volcanoes of Europe, Terra, Harpenen, England, 2001.

Scheidegger, A. E.: Theoretical Geomorphology, 2nd Edn., Springer, Berlin, 1970.

Schultz, R. A.: Limits on strength and deformation properties of jointed basaltic rock masses, Rock Mech. Rock Eng., 28, 1-15, 1995.

Sibbett, B. S.: Size, depth and related structures of intrusions under stratovolcanoes and associated geothermal systems, EarthSci. Rev., 25, 291-309, 1988.

Siebert, L., Simkin, T., and Kimberley, P.: Volcanoes of the World, 3rd Edn., University of California Press, Berkeley, 2010.
Simkin, T. and Siebert, L.: Volcanoes of the World, 2nd Edn., Tucson, AZ, Geoscience Press, 1995.

Simkin, T. and Siebert, L.: Earth's volcanoes and eruptions: an overview, in: Encyclopaedia of Volcanoes, edited by: Sigurdsson, H., New York, Academic Press, 249-261, 2000.

Sneddon, I. N. and Lowengrub, M.: Crack Problems in the Classical Theory of Elasticity, Wiley, New York, 1969.

Spence, D. A., Sharp, P. W., and Turcotte, D. L.: Buoyancy-driven crack-propagation - a mechanism for magma migration, J. Fluid Mech., 174, 135-153, 1987.

Spera, F. J.: Physical properties of magmas, in: Encyclopedia of Volcanoes, edited by: Sigurdsson, H., Academic Press, New York, 171-190, 2000.

Taisne, B., Tait, S., and Jaupart, C.: Conditions for the arrest of vertical propagating dyke, Bull. Volcanol., 73, 191-204, 2011.

Thompson, N., Watters, R. J., and Schiffman, P.: Stability analysis of Hawaiian Island flanks using insight gained from strength testing of the NSDP core, J. Volcanol. Geoth. Res., 171, 163-177, 2008.

Tibaldi, A.: Influence of volcanic cone morphology on dikes, Stromboli, Italy, J. Volcanol. Geoth. Res., 126, 79-95, 2003.

Tibaldi, A., Bistacchi, A., Pasquare, F. A., and Vezzoli, L.: Extensional tectonics and volcano lateral collapses: insights from Ollague volcano (Chile-Bolivia) and analogue modelling, Terra Nova, 18, 282-289, 2006.

Tibaldi, A., Corazzato, C., Gamberi, F., and Marani, M.: Subaerialsubmarine evidence of structures feeding magma to Stromboli Volcano, Italy, and relations with edifice flank failure and creep, Tectonophysics, 469, 112-136, 2009.

Walker, G. P. L.: The Hawaiian calderas: origin through loading by shallow intrusions, J. Geophys. Res., 93, 14773-14784, 1988.

Walker, G. P. L.: Basalt volcanoes and volcanic systems, in: Encyclopaedia of Volcanoes, edited by: Sigurdsson, H., New York, Academic Press, 283-289, 2000.

Wood, C. A. and Kienle, J.: Volcanoes of North America, Cambridge University Press, Cambridge, 1990.

Wyllie, D. C. and Mah, C.: Rock Slope Engineering, 4th Edn., Taylor and Francis, London, 2004. 